\title{
Synthesis of rodlike ruthenium(II) coordination polymers having metal-nitrogen and metal-carbon bonds in their main chains
}

\author{
Oliver Schmelz, Matthias Rehahn*
}

Deutsches Kunststoff-Institut (DKI) and Institut für Makromolekulare Chemie, Technische Universität Darmstadt, Petersenstr. 22, 64287 Darmstadt, Germany; Fax +49 (0)6151 / 292855; mrehahn@dki.tu-darmstadt.de

(Received: July 22, 2002; published: October 31, 2002)

\begin{abstract}
Well-defined coordination polymers are described whose main chains are held together by pseudo-octahedral ruthenium(II) complexes in which five ligands are nitrogen and one ligand is carbon. In the first step of polymer synthesis, the bis-tridentate ligand 4,4"-bis[4'-(2,2':6',2"-terpyridine)]-2',5'-dihexyl-p-terphenyl is treated with two equivalents of ruthenium(III) chloride. The resulting dinuclear metal-monomer is subsequently activated by exchanging the remaining three chloro ligands at each ruthenium center by acetone as a more easily substitutable ligand. The activated metal monomer is treated with equimolar amounts of 4,4"bis[4'-(6'-phenyl-2,2'-bipyridine)]-2',5'-dihexyl-p-terphenyl as a bis-tridentate ligand monomer. During this conversion, rodlike chains grow through the formation of two further metal-nitrogen bonds and one carbon-nitrogen bond at every ruthenium center. The homogeneous constitution of the readily soluble polymers is proven, and their degrees of polycondensation are roughly estimated to be $P_{\mathrm{n}} \geq 20$, using ${ }^{1} \mathrm{H}$ and ${ }^{13} \mathrm{C}$ NMR spectroscopy. UV-vis absorption spectra show the polymers to behave like chains of electronically independent metal complexes. Due to the carbon-ruthenium bond, however, $\lambda_{\max }$ appears at a longer wavelength (approx. $530 \mathrm{~nm}$ ) than in the related coordination compounds with only nitrogen-ruthenium bonds. There, $\lambda_{\max }$ is around $500 \mathrm{~nm}$.
\end{abstract}

\section{Introduction}

Constitutionally well-defined transition-metal coordination polymers are of considerable current interest because of their electronic, optical, magnetic and solution properties [1-26]. Moreover, they are key compounds at the borderline of macromolecular and supramolecular science. When readily soluble in conventional solvents and rod-like in shape, for example, they are fascinating self-organizing buildingblocks for multilayer systems [12,13] as well as important models for developing a profound understanding of polyelectrolyte behavior in solution [19]. Also, they seem to have a potential in fields like artificial photosynthesis, solar energy conversion and catalysis. Last but not least, the preparation of such compounds in a well-defined manner is still a challenge on its own, and thus a stimulating goal for synthetic polymer chemists.

Rod-like coordination polymers of general structure A can be created by catenating appropriately designed bis[2,2':6',2"-terpyridine]-based ligand monomers via (pseudo-)octahedral complexes of iron(II), ruthenium(II) or osmium(II). In all such 
polymers described so far in the literature, the metal centers only have nitrogen as ligand atoms. Well-defined polymers $\mathbf{B}$, on the other hand, where one or even more carbon-metal bonds are present in the complexes, are unknown to the best of our knowledge. However, it is of interest to also make these polymers $\mathbf{B}$ available because $(i)$ they should show electronic and optical properties quite different from those of polymers $\mathbf{A}$, (ii) their chains should have a more pronounced covalent character and should be even more stable than chains $\mathbf{A}$, and (iii) they have a lower or even vanishing ionic charge density, giving rise to clearly different properties in bulk and solution compared to systems like $\mathbf{A}$.

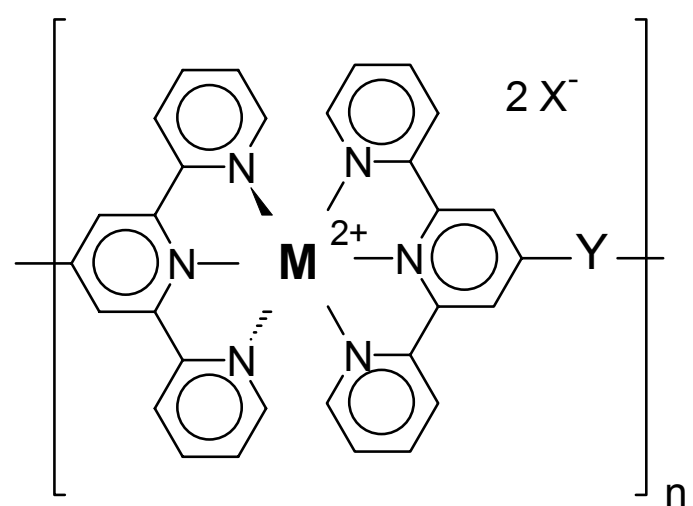

A

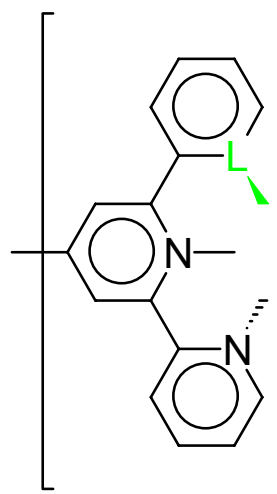

B

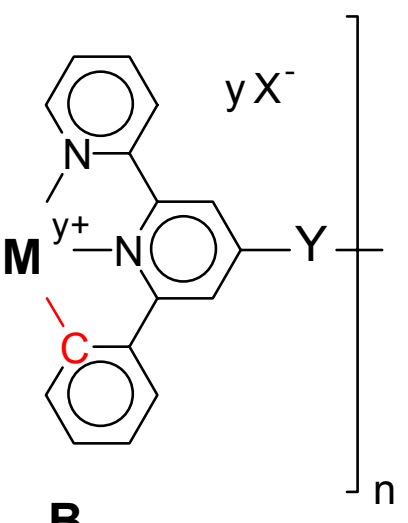

Fig. 1. General structures of rodlike coordination polymers $\mathbf{A}$ and their cyclometallated analogs $\mathbf{B}$; $\mathrm{M}$ : transition-metal ion, $\mathrm{X}$ : counter ion, $\mathrm{Y}$ : bridging unit, $L$ : $\mathrm{N}$ or $\mathrm{C}$

Recently, Constable, Sauvage and others developed synthetic methods which open up access to low-molecular-weight octahedral ruthenium(II)-polyimine complexes in which one carbon atom acts as a ligand in addition to five nitrogen atoms [27-46]. Provided it is possible to increase the efficiency of the complex-formation processes, it should be possible to also take advantage of these procedures for the successful preparation of multinuclear and thus polymeric coordination compounds. In order to gain a deeper insight into the structure-property relationships of multinuclear coordination polymers and to establish transition-metal coordination polymers in macromolecular science more deeply, we decided to develop such a synthetic access to rodlike coordination polymers of general structure $\mathbf{B}$.

In the first paper dealing with this topic, we shall now describe a straightforward synthesis leading to a polymer $\mathbf{B}$ which has one ruthenium-carbon bond in each metal complex $(L=N$ in Fig. 1). We shall report on the conversions used for the preparation of the required monomers, on model experiments performed to optimize the polymerization conditions, and on the synthesis of the desired rodlike but nevertheless readily soluble coordination polymers B. Finally, the results of UV-vis spectroscopic investigations shall be discussed. At the beginning, however, we shall sketch our considerations that led to the chosen target structures and to the selected synthetic strategy.

\section{Synthetic strategy}

In the first instance, we had to define the real constitution of our target polymers $\mathbf{B}$. This decision was made on the basis of recent work, where we prepared rodlike coordination polyelectrolytes 1 (Scheme 1) [19]. The rodlike shape of these polymers 
was achieved because the two 2,2':6',2"-terpyridine moieties of ligand monomer 2 are connected by an all-para linked terphenylene bridging unit. In order to ensure solubility of the rods 1 in conventional solvents such as dimethyl sulfoxide (DMSO) or dimethylacetamide (DMAc) - an essential prerequisite for profound polymer characterization - two solubilizing n-hexyl side chains were attached to each ligand monomer. As we could show that these polymers 1 fulfill all our expectations concerning shape and solubility, it was reasonable to define the constitutionally related polymer $\mathbf{7}$ as the target structure for our planned work.

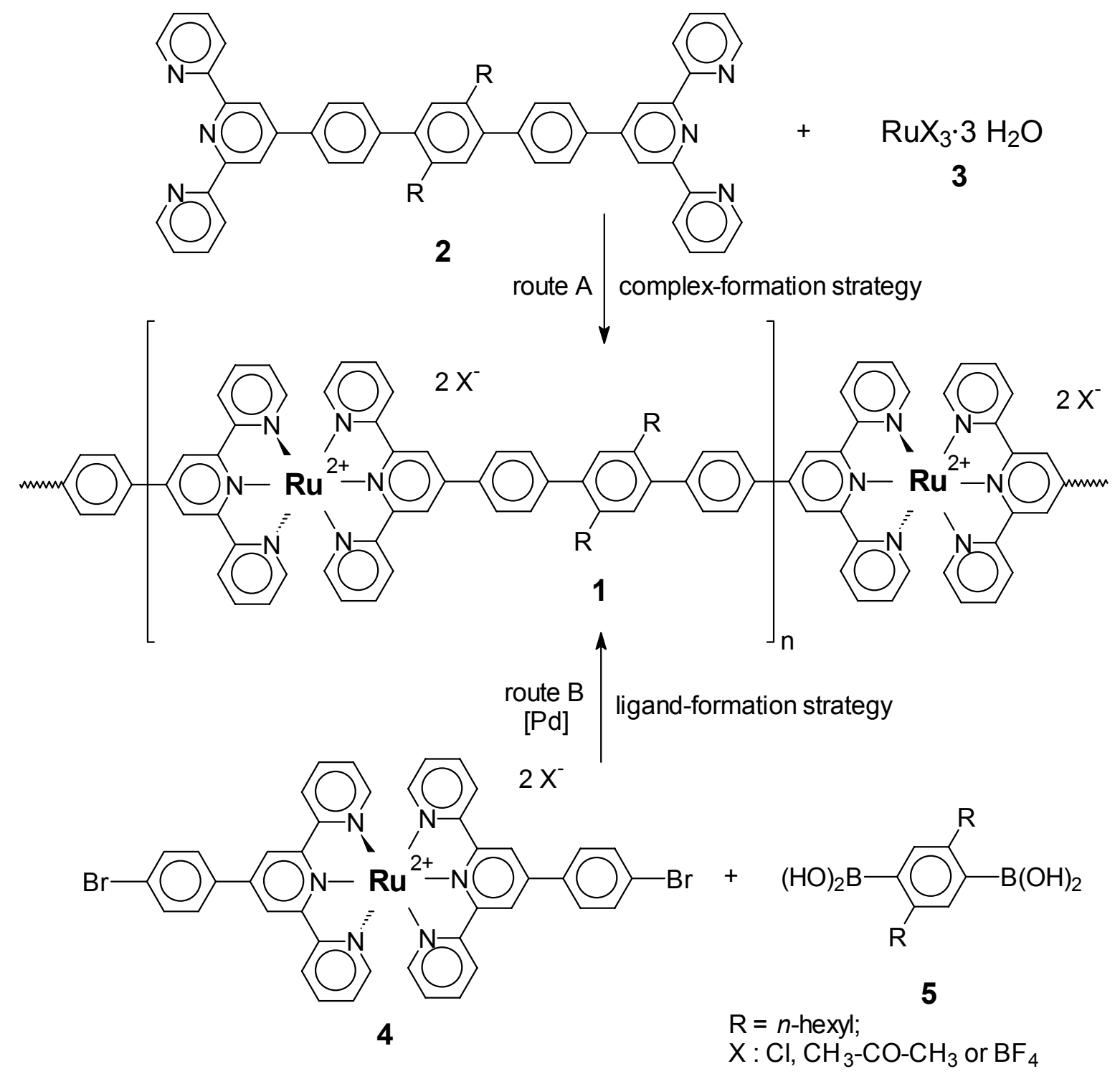

Scheme 1. Two competitive synthetic routes leading to coordination polymers 1

In the second instance, we had to decide how to build up such polymers 7. Again, our considerations were based on the work leading to polymers 1. For those polymers, we were able to show that the synthesis is successful only via the socalled 'complex-formation strategy' (route A). Here, chain growth occurs via formation of the octahedral $\left[\mathrm{RuN}_{6}\right]^{2+}$ motifs. The competitive 'ligand-formation strategy' (route $\mathrm{B}$ ), on the other hand, proved to be unsuitable. This failure is because the solubility of growing chains $\mathbf{1}$ is too low in all solvents appropriate for the Pd-catalyzed poly- 
condensation reaction. Hence, chains 1 already precipitate in the early oligomeric state, and further growth is prohibited.

It was reasonable to assume that the same failure will happen when the Pd-catalyzed Suzuki coupling reaction according to route $B$ is applied for the synthesis of the constitutionally related rodlike polymer 7 . This is certainly a pity because $\mathrm{Pd}$ catalyzed polycondensation of preformed $\left[\mathrm{RuN}_{5} \mathrm{C}\right]^{+}$complexes should represent a comfortable way to polymers like 7: the critical formation of $\left[R u(t p y){ }_{1}(\text { phbpy })_{1}\right]^{+}$ complexes (tpy: 2,2':6',2"-terpyridine, phbpy: 6'-phenyl-2,2'-bipyridine) could be avoided as the chain growth reaction, and the functionalized mononuclear metal complexes used as the monomers could readily be purified prior to polymer synthesis. However, the expected failure of route B was the determining argument for our final decision to prepare the new polymers 7 via the intrinsically more difficult complex-formation strategy and thus in analogy to route $A$.

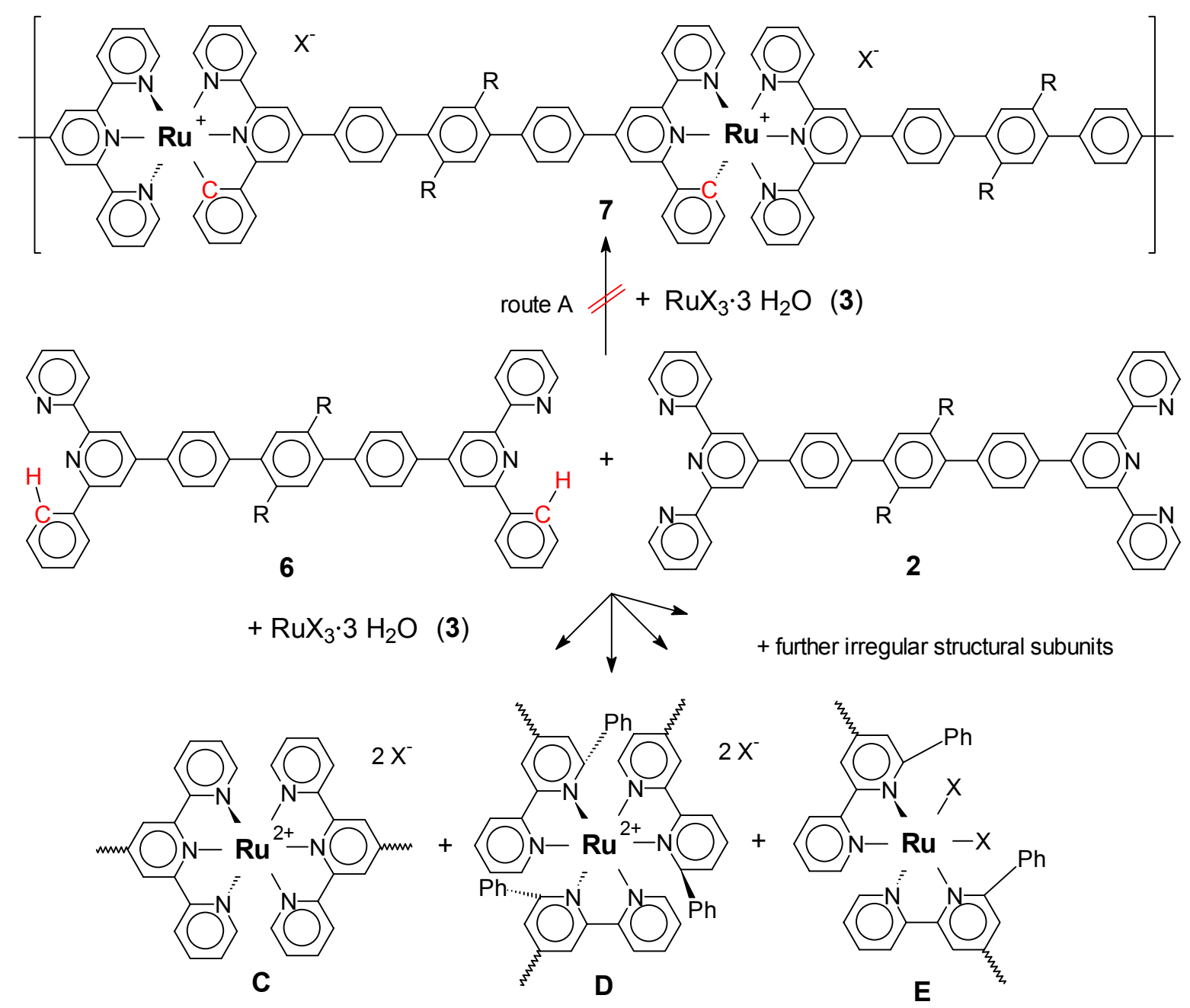

Scheme 2. Structure of polymer $\mathbf{7}$, and possible side reactions that may occur when mixtures of ligand monomers $\mathbf{2}$ and $\mathbf{6}$ are treated directly with the required amount of activated metal monomer 3

Hence, in order to make available constitutionally homogeneous polymers 7 of high molecular weights, it was necessary to develop an efficient synthetic procedure that ensures highly selective and quantitative formation of the $\left[\mathrm{RuN}_{5} \mathrm{C}\right]^{+}$motif. For this purpose, direct conversion of a 1:1 mixture of ligand monomers 2 and $\mathbf{6}$ with an 
adequate quantity of activated ruthenium(III) 3 is certainly not the recommended way: this process will result in the formation of a mixture of different complexes including $\mathbf{C}$ - E. Existence of such complexes in chains like 7 will cause bent, branched and crosslinked products of irregular constitution (Scheme 2).

We were looking, therefore, for a strategy which allows us to control the complex formation reaction as precisely as possible, i.e., to ensure the coordination of exactly one ligand monomer 2 and one ligand monomer 6, both as tridentate ligands, at every ruthenium center. The selected way to form exclusively $\left[R u(t p y)_{1}(\text { phbpy })_{1}\right]^{+}$ motifs during the polymer synthesis is represented by the two-step strategy shown in Scheme 3. Here, ligand monomer $\mathbf{2}$ is first transformed into the dinuclear metal monomer 8 which is treated, after appropriate activation, with the second ligand monomer 6.

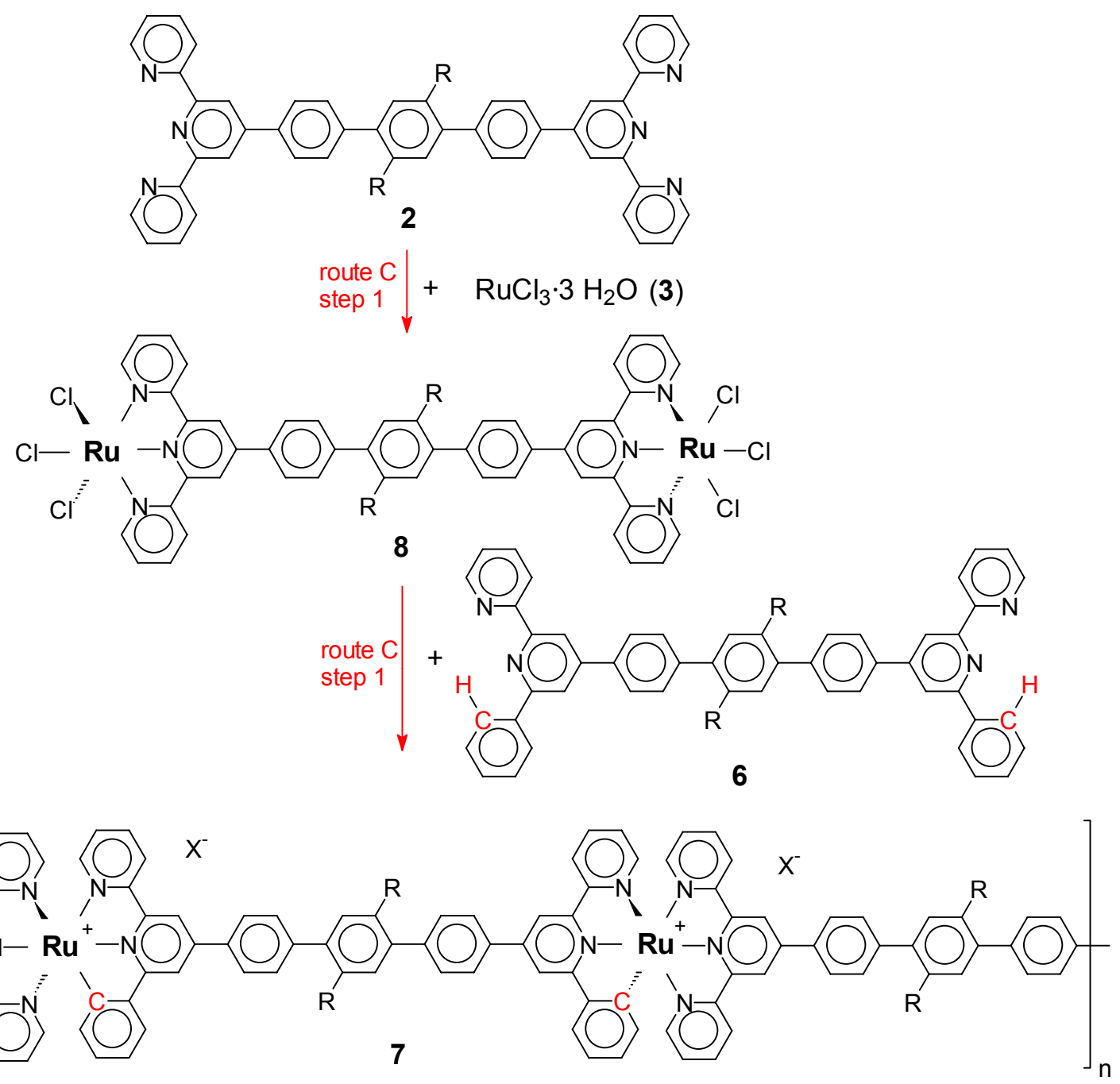

Scheme 3. Synthetic route selected for the preparation of coordination polymers 7

\section{Results and discussion}

\section{Synthesis of ligand monomers 2 and $\mathbf{6}$}

The synthesis of coordination polymers 7 according to Scheme 3 requires the bistridentate chelating ligands 2 and $\mathbf{6}$ as monomers. 4,4"-Bis[4'-(2,2':6',2"-terpyridine)]2',5'-dihexyl-p-terphenyl 2 was synthesized according to Scheme 4. 


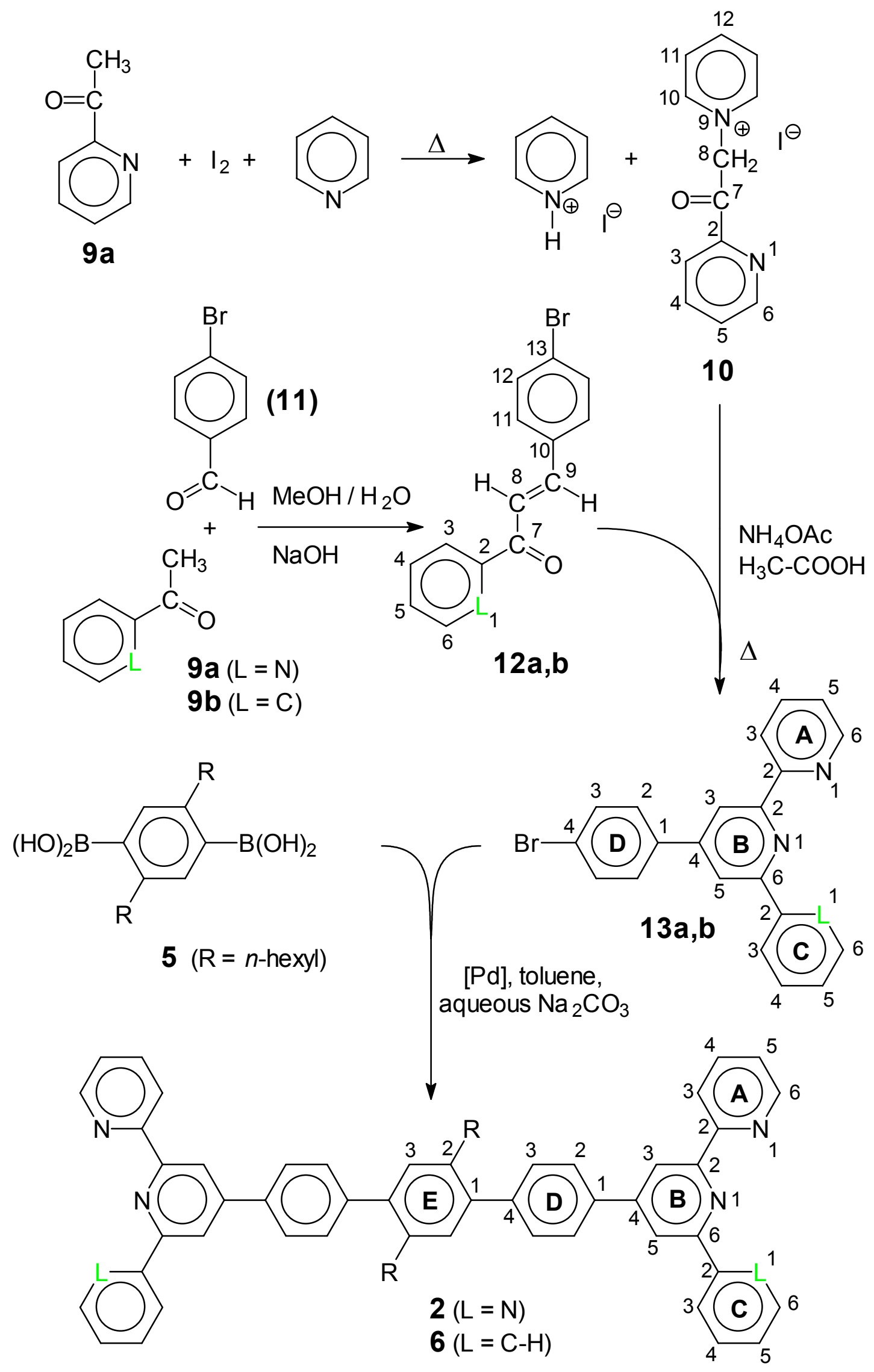

Scheme 4. Synthetic route used to prepare monomers 2 and $\mathbf{6}$, and numbering of the hydrogens and carbons used for NMR signal assignment (see below) 
2-Acetylpyridine 9a was dissolved in pyridine and converted in a King reaction into 1(2-pyridacyl)pyridinium iodide 10 by adding equimolar amounts of iodine. The azachalcone 4-bromo-2-cinnamoylpyridine 12a, on the other hand, was prepared in approx. $85 \%$ yield by treating $p$-bromobenzaldehyde 11 and 2-acetylpyridine 9 a in the presence of sodium hydroxide. Subsequently, 12a was treated with 1-(2pyridacyl)pyridinium iodide $\mathbf{1 0}$ in a mixture of ammonium acetate and acetic acid. Pure 4'-(p-bromophenyl)-2,2':6',2"-terpyridine 13a was obtained in approx. $50 \%$ yield after recrystallization. Finally, two equivalents of 13a were treated with 2,5-dihexylbenzene-1,4-diboronic acid 5 [47] in the heterogeneous mixture of toluene and $1 \mathrm{M}$ aqueous $\mathrm{Na}_{2} \mathrm{CO}_{3}$, using $1 \mathrm{~mol}-\%$ of $\left[\mathrm{Pd}\left(\mathrm{PPh}_{3}\right)_{4}\right]$ as the precursor complex of the catalytically active Pd-species [47-49]. Pure ligand monomer 4,4"-bis(2,2':6',2"terpyridine)-2',5'-di-n-hexyl-p-terphenyl 2 was isolated in $85 \%$ yield.

The second ligand monomer required, i.e., 4,4"-bis(6'-phenyl-2,2'-bipyridine)-2',5'-di$\mathrm{n}$-hexyl-p-terphenyl $\mathbf{6}$, could be prepared in analogy to compound $\mathbf{2}$. The only difference is the application of acetylbenzene $9 \mathrm{~b}$ instead of acetylpyridine $9 \mathrm{a}$, leading to chalcone derivative 12b. Again, the final Pd-catalyzed condensation reaction gave the desired ligand monomer 6 in approximately $80 \%$ yield.
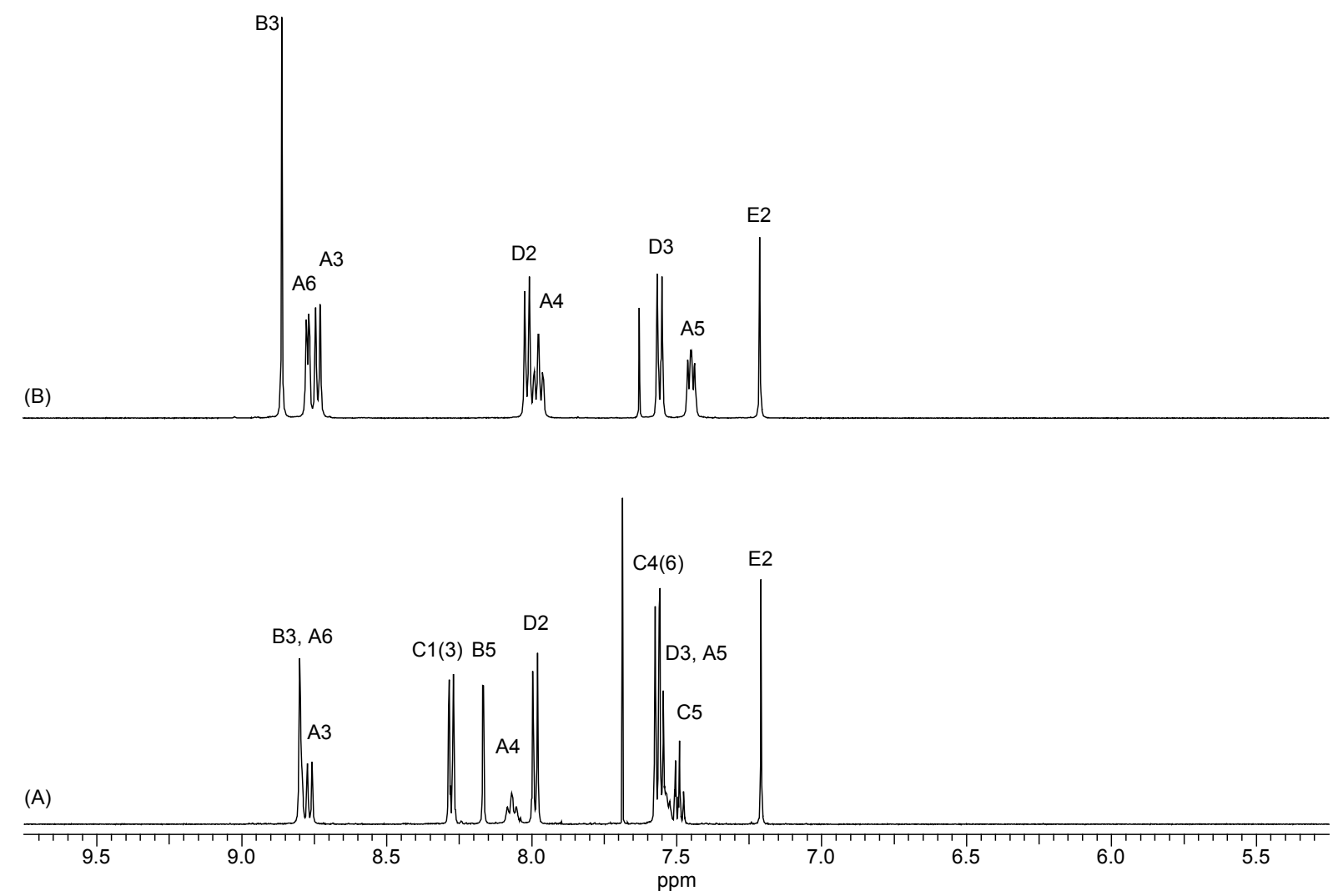

Fig. 2. Aromatic regions of the ${ }^{1} \mathrm{H}$ NMR spectra of ligand monomers $6(A)$ and $\mathbf{2}(B)$, recorded in a 6:1 (v/v) mixture of $\mathrm{CDCl}_{3}$ and $\mathrm{DMSO}-d_{6}$ at room temperature. Signal assignment is made according to the numbering given in Scheme 4

The constitution of monomers $\mathbf{2}$ and $\mathbf{6}$ as well as of all intermediates such as $\mathbf{1 0}$, 12a,b and 13a,b was verified using ${ }^{1} \mathrm{H}$ and ${ }^{13} \mathrm{C}$ NMR spectroscopy. As a representative example, Figs. $2 A, B$ and $3 A, B$ display the aromatic regions of the ${ }^{1} \mathrm{H}$ and ${ }^{13} \mathrm{C}$ NMR spectra of monomers 2 and $\mathbf{6}$, respectively. As one can see from signal assignment, only absorptions are detectable that unambiguously correspond to 
monomers 2 and 6 . The purity of the best monomers was estimated to be $>98 \%\left({ }^{1} \mathrm{H}\right.$ NMR). Elemental analysis and mass spectrometry further supported the constitution and purity of 2 and $\mathbf{6}$.
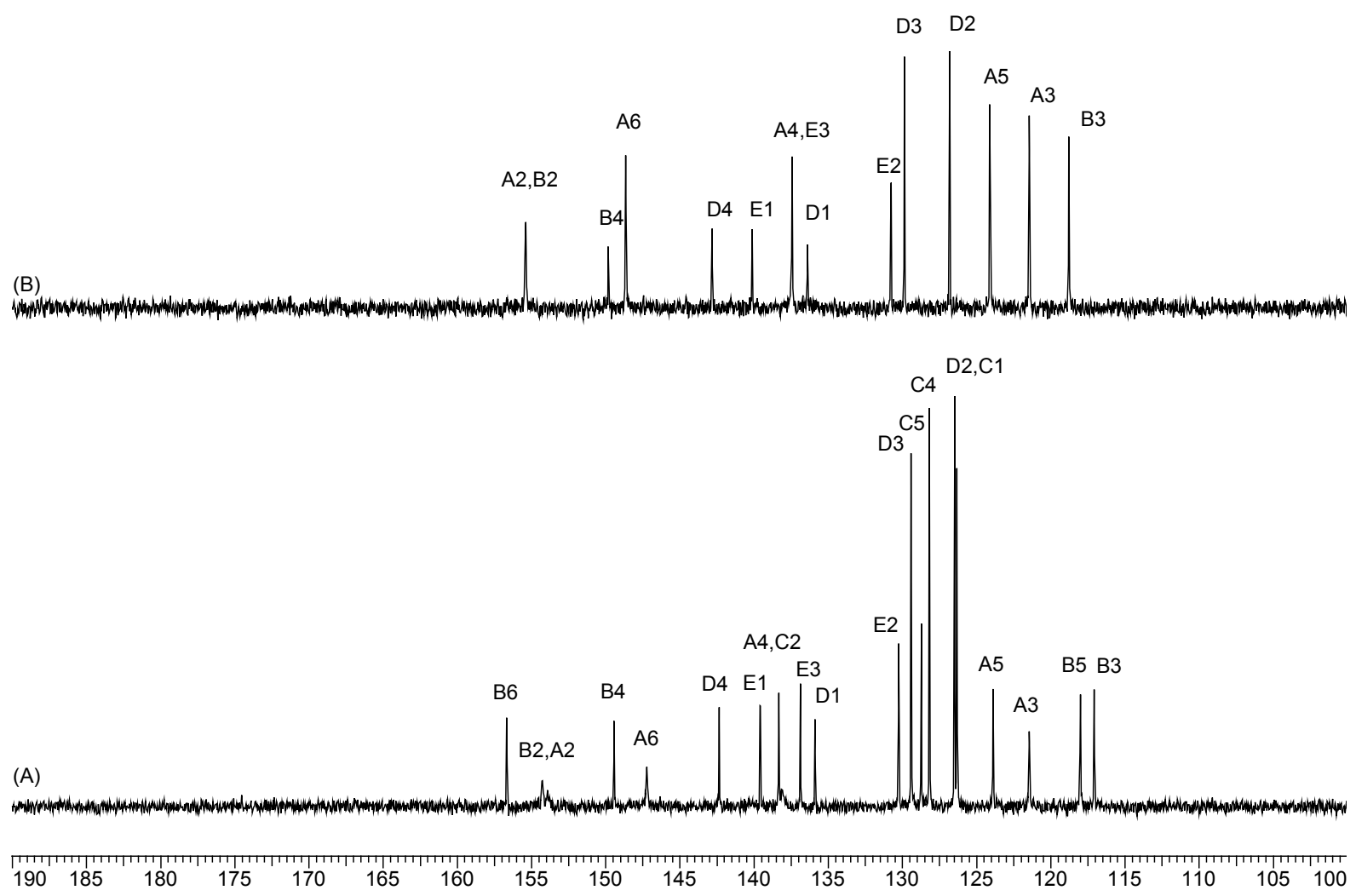

Fig. 3. Aromatic regions of the ${ }^{13} \mathrm{C}$ NMR spectra of ligand monomers $6(A)$ and $2(B)$, recorded in a $6: 1(\mathrm{v} / \mathrm{v})$ mixture of $\mathrm{CDCl}_{3}$ and $\mathrm{DMSO}-d_{6}$ at room temperature. Signal assignment is made according to the numbering given in Scheme 4

\section{Synthesis of metal monomer 8}

The dinuclear ruthenium compound $\mathbf{8}$ was the required metal monomer for the synthesis of coordination polymers 7 according to Scheme 3 . Its synthesis was assumed to be possible in analogy to the procedure published for the preparation of $\left[\mathrm{Ru}(\mathrm{tpy})_{1} \mathrm{Cl}_{3}\right]$. In order to adapt the published reaction conditions for the preparation of 8 , we selected $13 a$ as the model ligand (Scheme 5). Moreover, the products $14 a$ and 15 thus obtained were needed as reference compounds for the detailed analysis of the NMR spectra of polymers 7.

In our first investigations, 4'-(p-bromophenyl)-2,2':6',2"-terpyridine ( $p$ Brph-tpy) 13a was treated with $\mathrm{RuCl}_{3} \cdot 3 \mathrm{H}_{2} \mathrm{O}, 3$, in dry ethanol. As the obtained complex 14a (approx. 85\% yield) could not be analyzed directly using spectroscopic methods like NMR because of its low solubility, representative samples of the product mixture were treated with one equivalent of $13 a$ or 16 to form the complexes [Ru(pBrphtpy $\left.)_{2}\right]^{2+} 15 a$ and $[R u(p B r p h-t p y)(p C l-t p y)]^{2+} 15 c$, respectively, which are easy to characterize. Prior to this conversion, however, it proved necessary to activate 14a via treatment with $\mathrm{AgBF}_{4}$ in acetone. During this process leading to activated $14 \mathrm{a}^{*}$, the chloro ligands of $14 \mathrm{a}$ are removed as $\mathrm{AgCl}$, and simultaneously substituted by the more labile acetone ligands. The highly reactive intermediate $14 a^{*}$ formed was then heated with one equivalent of $13 a$ or 16 in n-butanol or dimethylacetamide. 


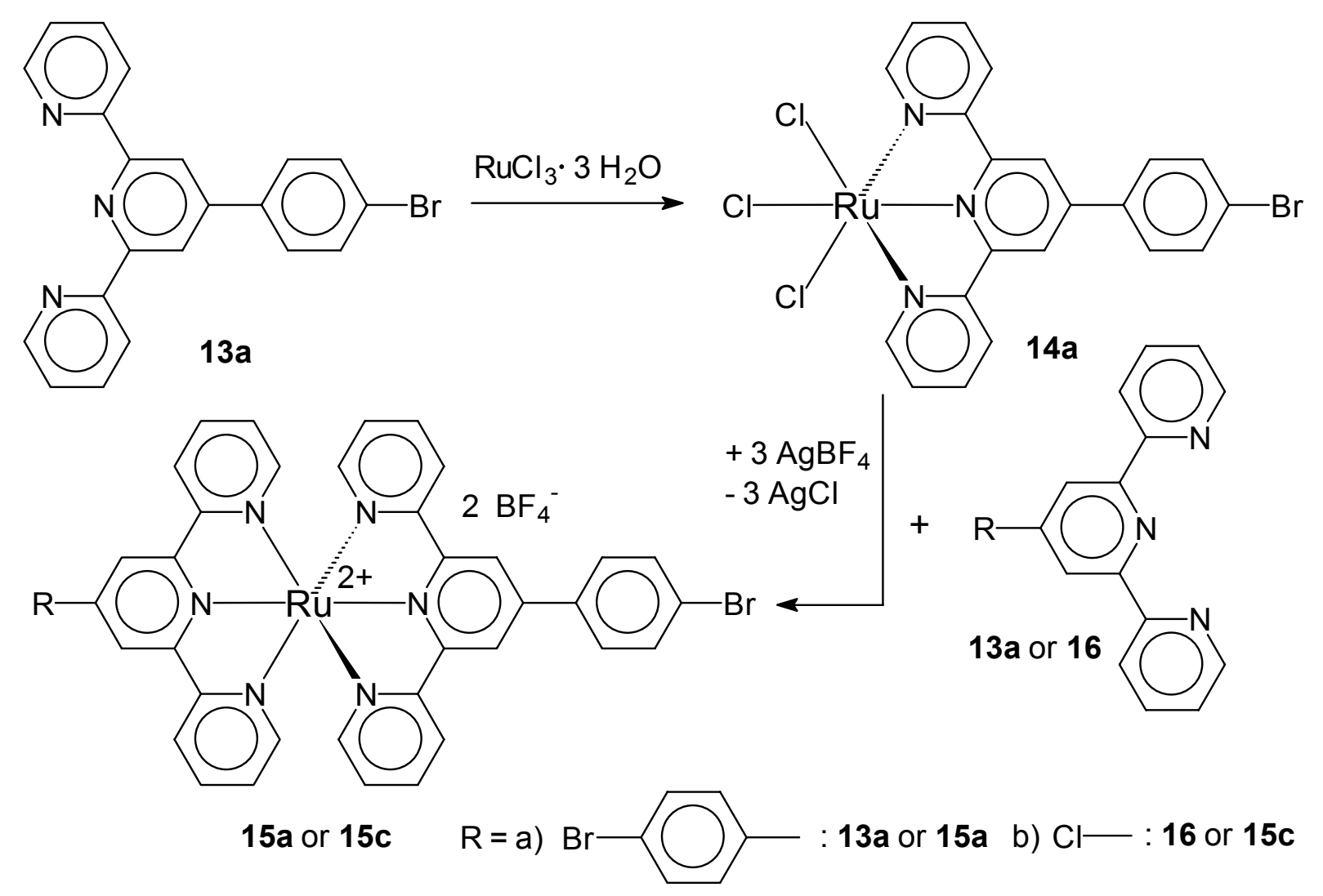

Scheme 5. Model reactions performed in order to optimize the reaction conditions leading to metal monomer 8

After 1 day, representative samples of the resulting product were analyzed using NMR. It became evident that highly pure $15 a / 15 c$ was formed. Hence, very pure 14a was obviously used as the starting material in this model conversion. Fig. 4 shows the aromatic regions of the ${ }^{1} \mathrm{H}$ NMR spectrum of the $p$ Brph-tpy ligand 13a $(\mathrm{A})$ and of a representative product mixture 15 a obtained according to Scheme 5. All absorptions observed in Fig. 4B correspond to the hydrogens of $15 \mathrm{a}$, proving the homogeneous and selective conversion process as well as the high purity of the starting material 14a.

Based on this promising model experiment, we concluded that the reaction conditions selected for the synthesis of $\mathbf{1 4 a}$ should also be appropriate for the preparation of the required metal monomer $\mathbf{8}$. Therefore, the bis-chelating ligand monomer $\mathbf{2}$ was now treated with $\mathrm{RuCl}_{3} \cdot 3 \mathrm{H}_{2} \mathrm{O}, 3$, under exactly the same conditions (Scheme 6, step 1). In most experiments, an excess of 3 (approx. 4 eq.) was used to prevent free ligand moieties in monomer 8.

Metal monomer 8 was obtained from this conversion as a dark-brown solid in $>90 \%$ yield. Again, the constitution and purity of the obtained dinuclear ruthenium(III) compound 8 could not be analyzed directly using NMR spectroscopy. Therefore, representative samples of $\mathbf{8}$ were activated using $\mathrm{AgBF}_{4} /$ acetone and then treated with two equivalents of 4'-chloro-2,2':6',2"-terpyridine ( $p$ Cl-tpy) 16 (Scheme 6, step 2). Representative samples of the product mixture 17 a were analyzed using ${ }^{1} \mathrm{H}$ and ${ }^{13} \mathrm{C}$ NMR spectroscopy. Fig. 5 displays characteristic ${ }^{1} \mathrm{H}$ NMR spectra of the model compound 17a thus obtained. 


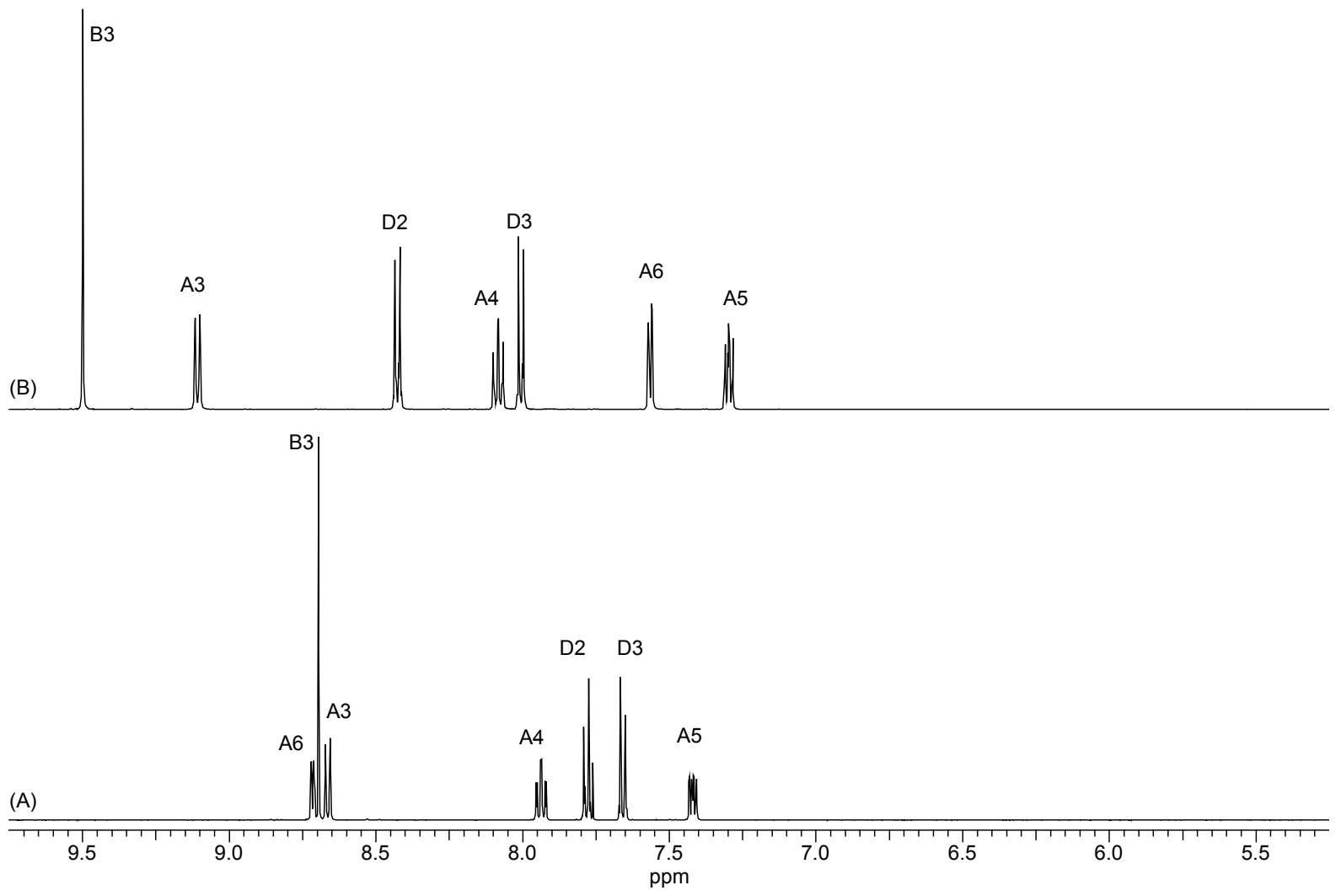

Fig. 4. Aromatic regions of the ${ }^{1} \mathrm{H}$ NMR spectra of ligand $13 a(A)$ and of $[R u(p B r p h-$ tpy) $\left.{ }_{2}\right]^{2+} 15 a(B)$, recorded in a $4: 1(\mathrm{v} / \mathrm{v})$ mixture of $\mathrm{CDCl}_{3}$ and $\mathrm{DMSO}^{-d_{6}}(\mathrm{~A})$ and DMSO- $d_{6}(B)$ at room temperature. Signal assignment is made according to the numbering given in Scheme 4

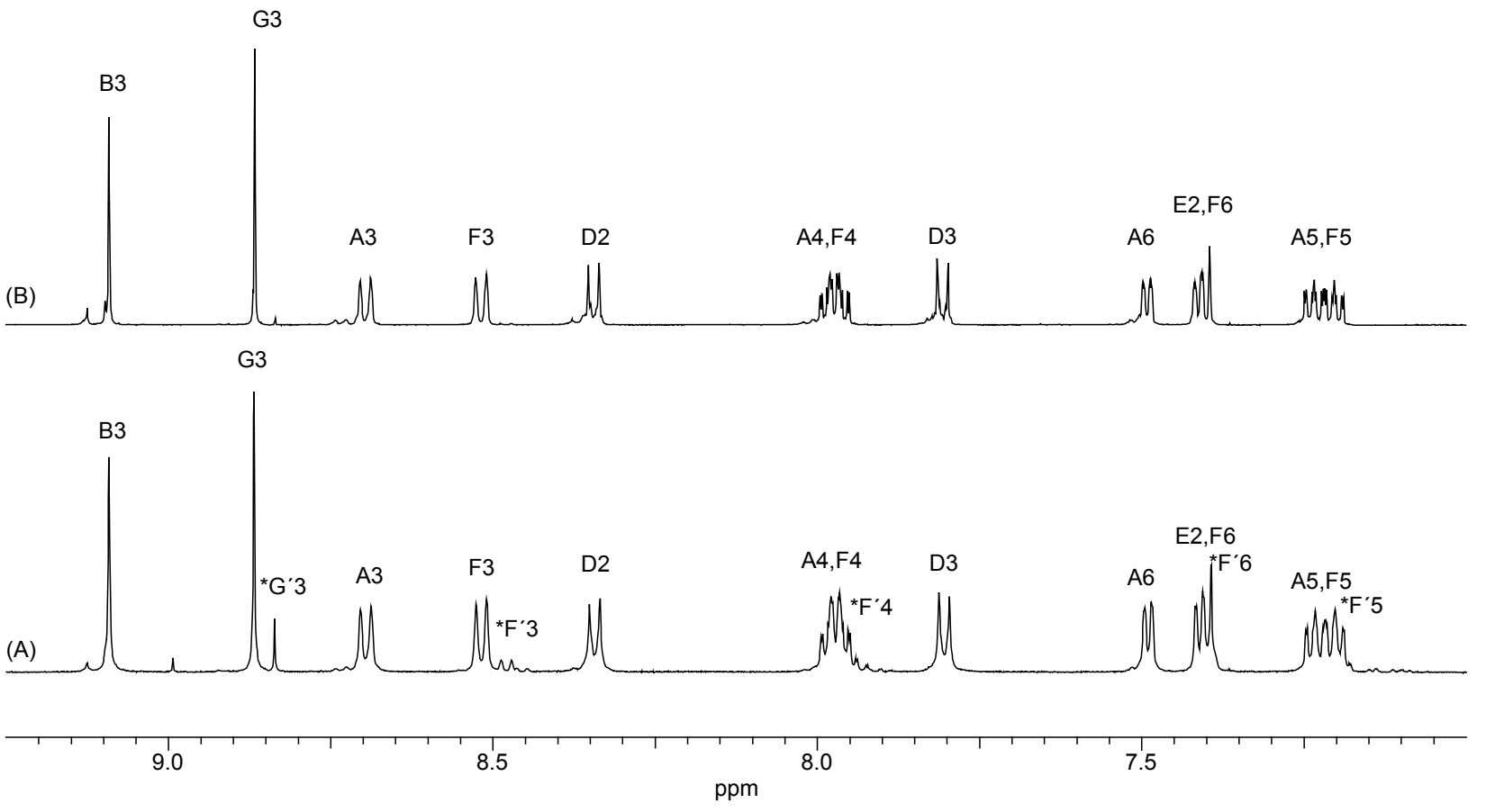

Fig. 5. Aromatic region of ${ }^{1} \mathrm{H}$ NMR spectra of the pure dinuclear model complex $17 \mathrm{a}$ $(B)$ in comparison to representative samples of the reaction mixture $(A)$, recorded in $\mathrm{CD}_{3} \mathrm{CN}$ at room temperature. Signal assignment is made according to the numbering given in Scheme 4. See text for details 
As one can see from signal assignment, all the intensive absorptions correspond to model complex 17a. The small signals that are additionally observable in Fig. 5A (indicated by asterisks) could be assigned to the mononuclear complex $[\mathrm{Ru}(p \mathrm{Cl}-$ tpy $\left.)_{2}\right]^{2+}$ which is formed because some traces of the excess of $\mathbf{3}$ used in the first step of this entry were still present. By carefully adjusting the excess of $\mathbf{3}$, the reaction conditions and the work-up procedure, model compounds 17a could be obtained in which this impurity is no longer detectable (see Fig. 5B). Therefore, the purity of monomer 8 formed according to Scheme 6 was judged to be sufficient for the subsequent polymer synthesis. This is in particular true because there are, in addition to the small absorptions of the $\left[\mathrm{Ru}(p \mathrm{Cl} \text {-tpy })_{2}\right]^{2+}$ impurity, no further signals observable in these spectra that might point towards the presence of additional impurities.

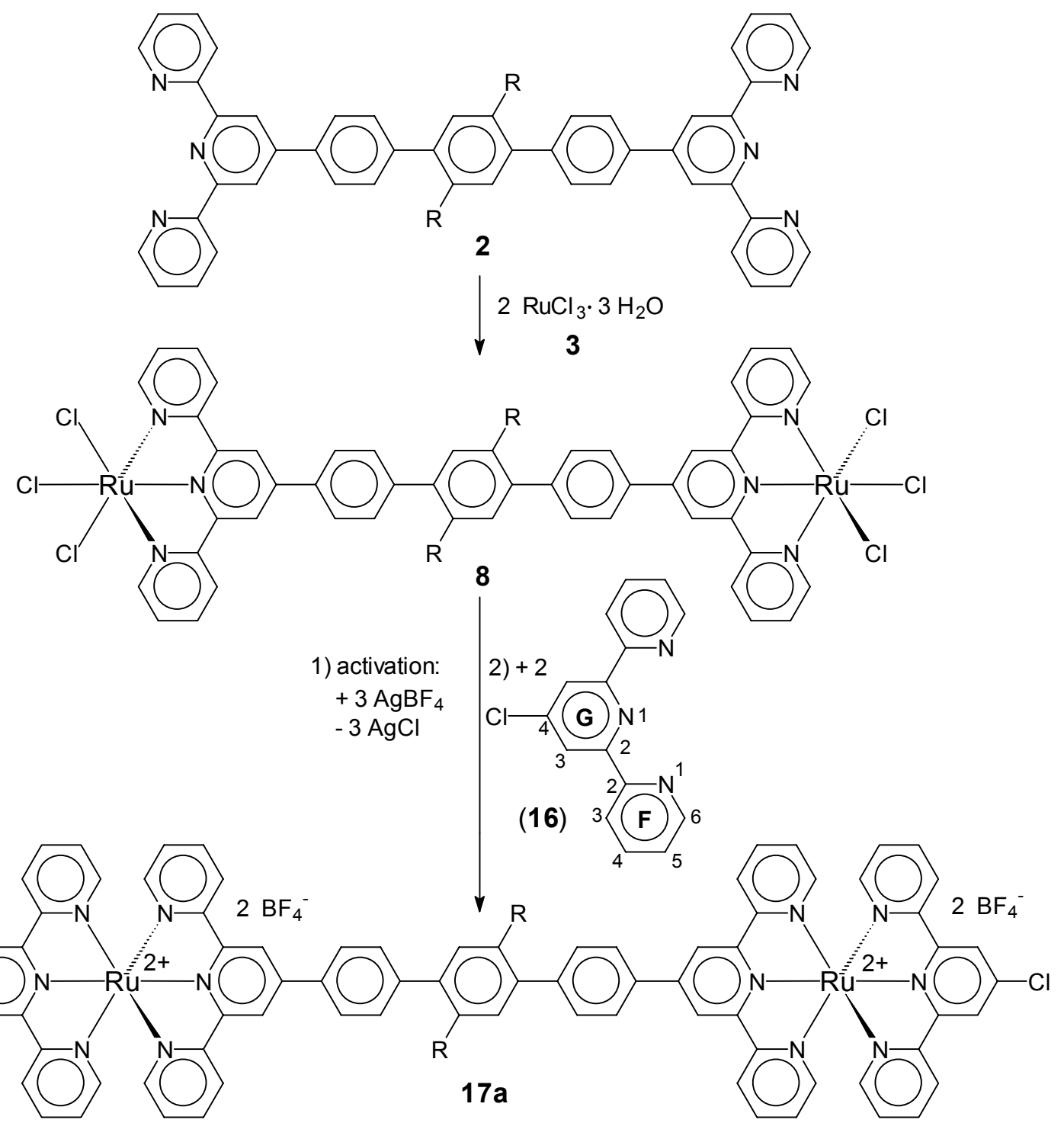

Scheme 6. Synthesis of metal monomer $\mathbf{8}$, and model conversion performed to analyze its purity

\section{Optimization of the polymerization conditions}

In order to find out appropriate reaction conditions for the polymer synthesis leading to a highly selective and quantitative conversion of $\mathbf{6}$ and $\mathbf{8}$ to high-molecular-weight 
polymers 7 , we performed studies on low-molecular-weight model compounds. The first model studies were carried out in particular to select conditions that guarantee the formation of $\left.\left[\mathrm{Ru}(\mathrm{tpy})_{1} \text { (phbpy) }\right)_{1}\right]^{+}$motifs, containing one carbon-ruthenium bond, without side reactions. The selected experiment is shown in Scheme 7. 14a was used here as the reference compound for metal monomer 8. After activation using $\mathrm{AgBF}_{4} /$ acetone, 14a* was treated in various solvents with equimolar amounts of $4^{\prime}-$ (p-bromophenyl)-6'-phenyl-2,2'-bipyridine, 13b (Scheme 7).

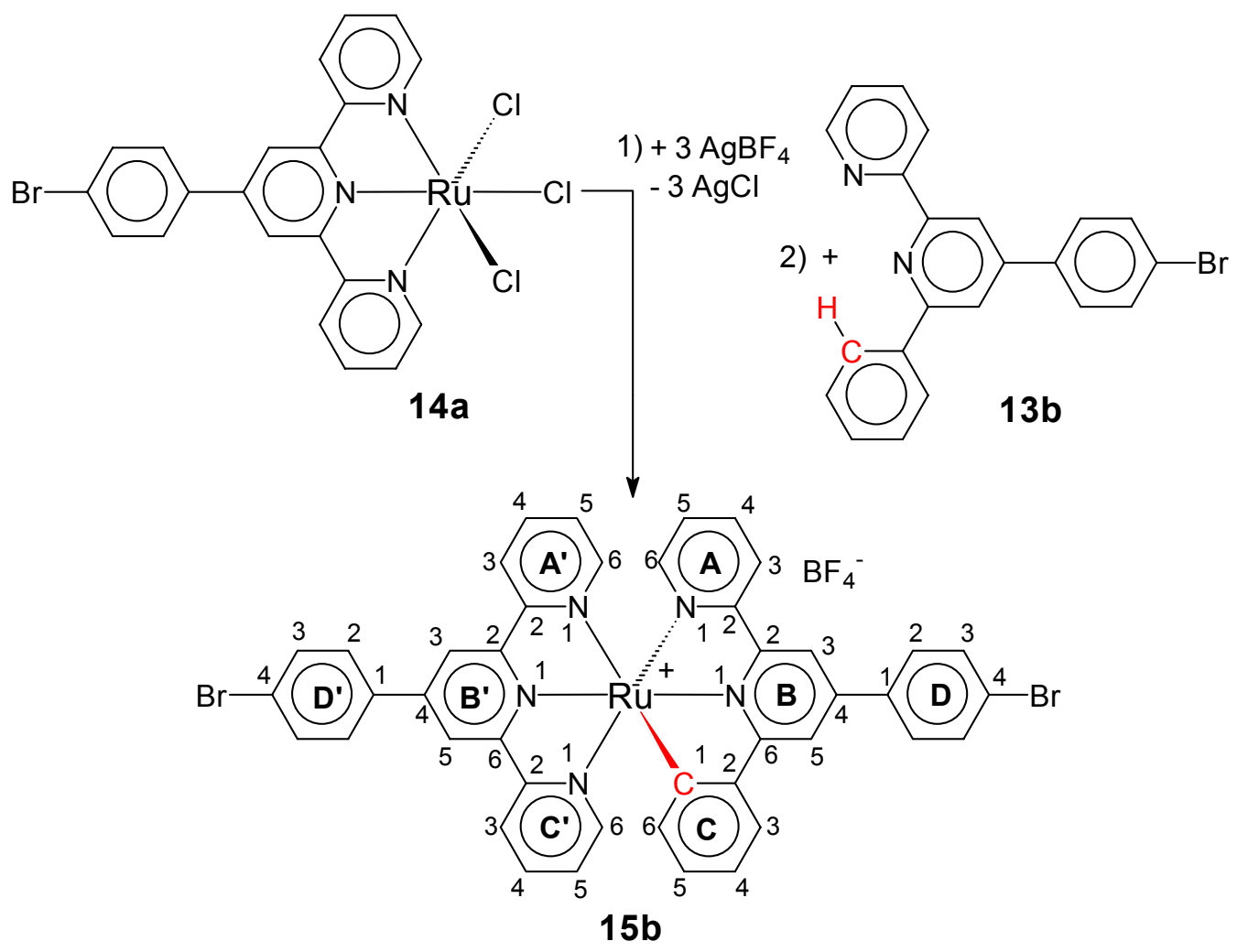

Scheme 7. Model reaction performed in order to optimize the reaction conditions leading to coordination polymer 7

A nearly quantitative formation of complex $15 \mathrm{~b}$ was found after 1 day heating when the conversion was performed in DMAc. All absorptions observed in the recorded NMR spectra correspond unambiguously to the desired model complex $\mathbf{1 5 b}$, and neither the ${ }^{1} \mathrm{H}$ nor the ${ }^{13} \mathrm{C}$ NMR spectra showed any evidence of remaining starting materials. In particular, we did not find further complexes in which, for example, 13b acts only as a bidentate ligand. Figs. 7A and $8 \mathrm{~A}$ display the aromatic regions of typical ${ }^{1} \mathrm{H}$ and ${ }^{13} \mathrm{C}$ NMR spectra, respectively, of a representative complex $15 \mathrm{~b}$. This statement is further supported by $2 \mathrm{D}$ NMR spectra: Fig. 6 displays the ${ }^{1} \mathrm{H}{ }^{13} \mathrm{C}$ COSY NMR spectrum of model complex $15 \mathrm{~b}$ as an example.

To summarize, activation of metal monomer 8 using $\mathrm{AgBF}_{4} /$ acetone, and using DMAc as solvent for the subsequent complex formation reaction, should be well appropriate for the formation of $\left[\mathrm{Ru}(\mathrm{tpy})_{1}(\text { phbpy })_{1}\right]^{+}$motifs of polymer 7 .

A second series of model investigations was performed in order to evaluate the quality of 6 as ligand monomer, and to confirm the above reaction conditions as being suitable for the planned polymer synthesis. The conversion shown in Scheme 8 , leading to the dinuclear complex $17 \mathrm{~b}$, was selected as the model reaction here. 


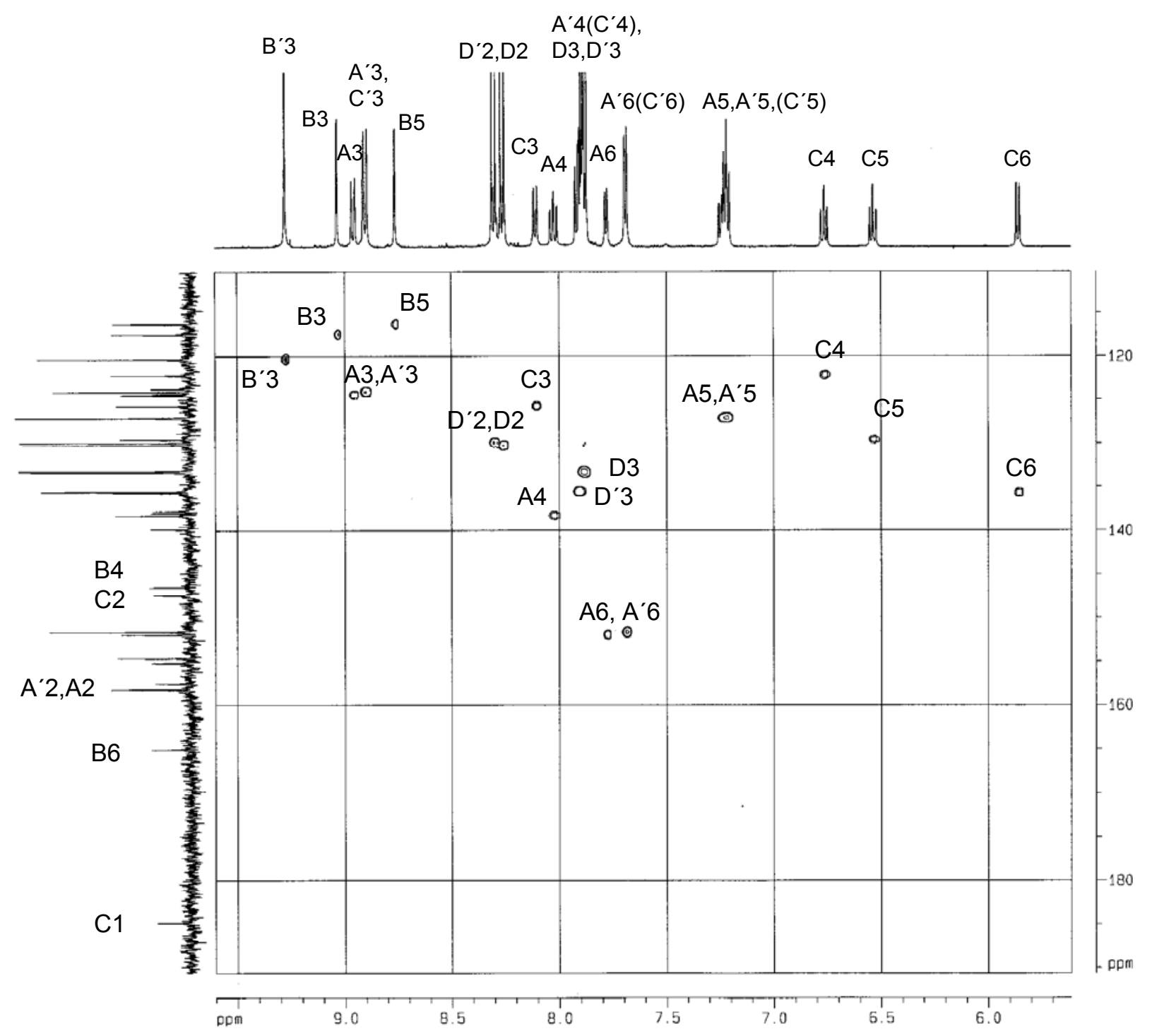

Fig. 6. ${ }^{1} \mathrm{H}{ }^{13} \mathrm{C}$ COSY NMR spectrum of the mononuclear model complex $15 \mathbf{b}$, recorded in acetone- $d_{6}$ at room temperature. Signal assignment is made according to the numbering shown in Scheme 4

17b was prepared by conversion of two equivalents of activated mononuclear complex 18 with one equivalent of ligand monomer 6 . The progress of conversion was monitored using NMR. Again, DMAc was found to be an appropriate solvent, but clearly longer reaction times were found to be necessary for complete conversion. Under optimum conditions, finally, complex $17 \mathrm{~b}$ was formed in yields of $>95 \%$ (NMR). Fig. 7B shows the aromatic region of the ${ }^{1} \mathrm{H}$ NMR spectrum of a representative product mixture obtained according to Scheme 8; Fig. 8B shows the corresponding ${ }^{13} \mathrm{C}$ NMR spectrum.

According to the given signal assignment, all intensive absorptions observed in these spectra correspond to the desired model complex $17 \mathrm{~b}$. Comparison of these spectra with those of the starting material 6 (Figs. $2 \mathrm{~B}$ and $3 \mathrm{~B}$ ) makes clear that a nearly quantitative conversion was reached under these latter conditions, and almost no evidence is found of remaining starting materials or the formation of side products. However, when the reaction conditions are not properly selected, absorptions of side products are clearly observable in the NMR spectra. 


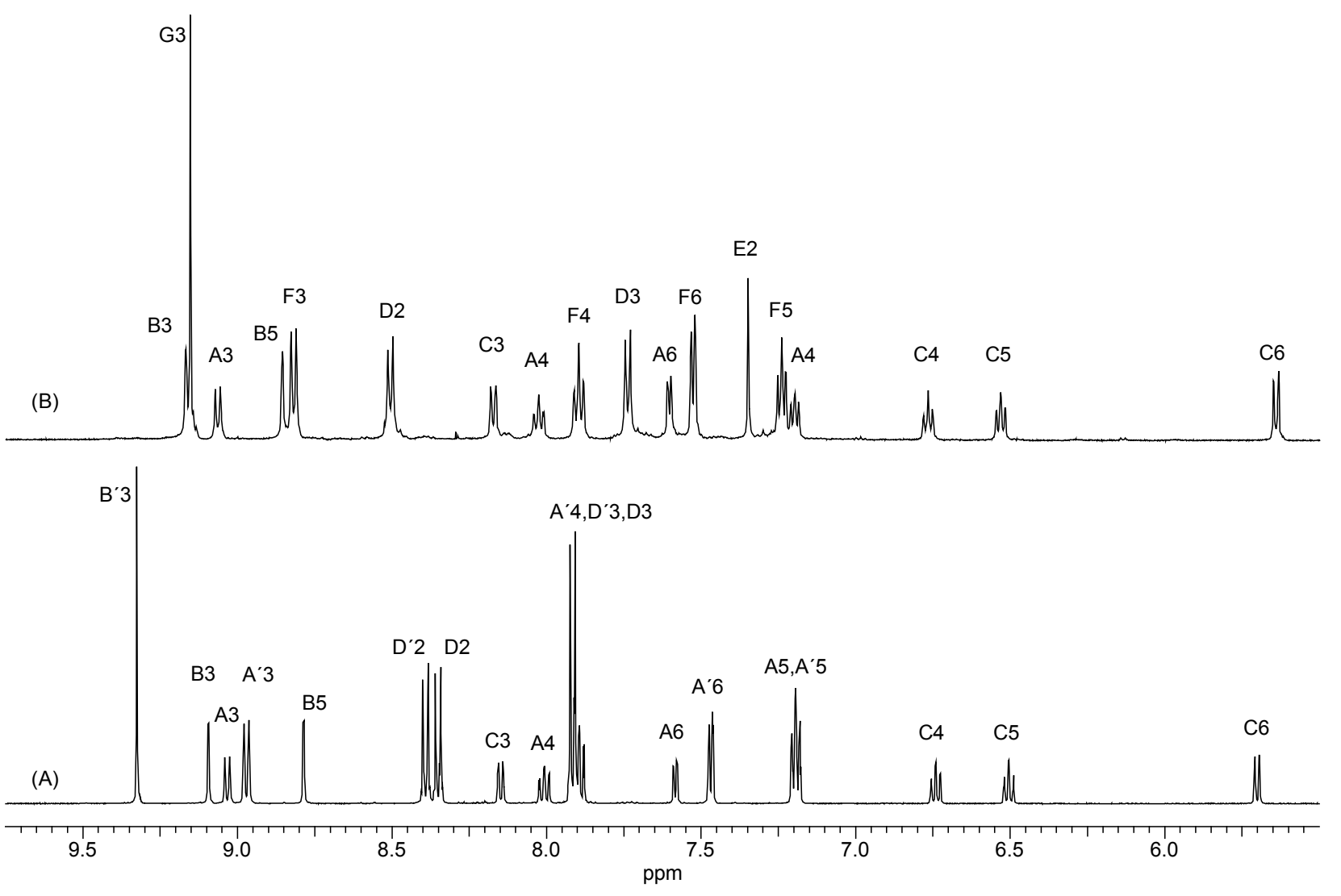

Fig. 7. Aromatic regions of the ${ }^{1} \mathrm{H}$ NMR spectra of the mononuclear model complex $15 \mathrm{~b}(\mathrm{~A})$ and of the dinuclear model complex $17 \mathrm{~b}(\mathrm{~B})$, recorded in DMSO- $d_{6}$. Signal assignment is made according to Scheme 4

(B)
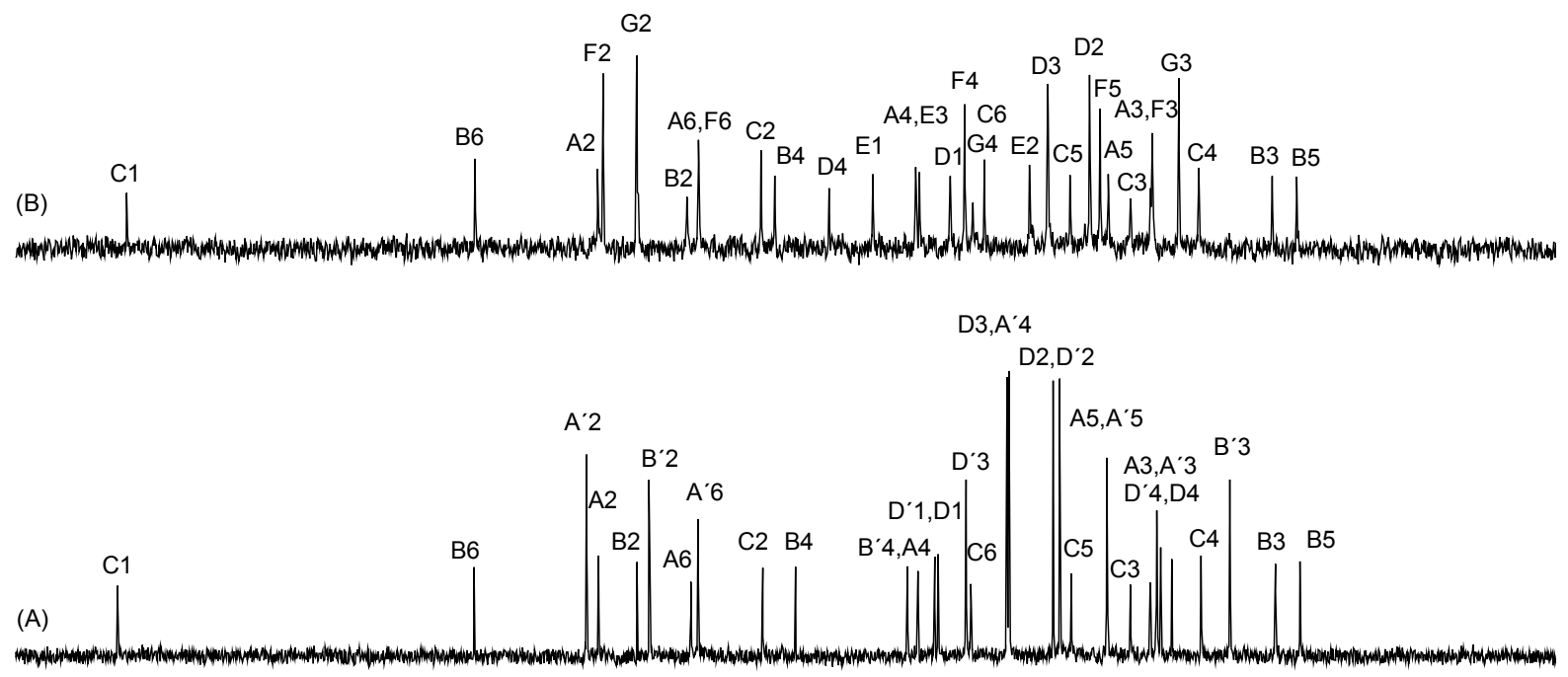

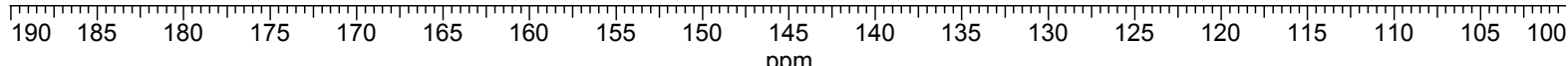

Fig. 8. Aromatic regions of the ${ }^{13} \mathrm{C}$ NMR spectra of the mononuclear model complex 15b (A), and of the dinuclear model complex 17b (B), recorded in DMSO- $d_{6}$. Signal assignment is made according to Scheme 4 
There is some evidence that these side products contain complexes like $\mathbf{D}$ and $\mathbf{E}$ shown in Scheme 2 where the phenylbipyridine chelating moieties act as bidentate ligands. Hence, care must be taken to adhere to the exact reaction conditions.

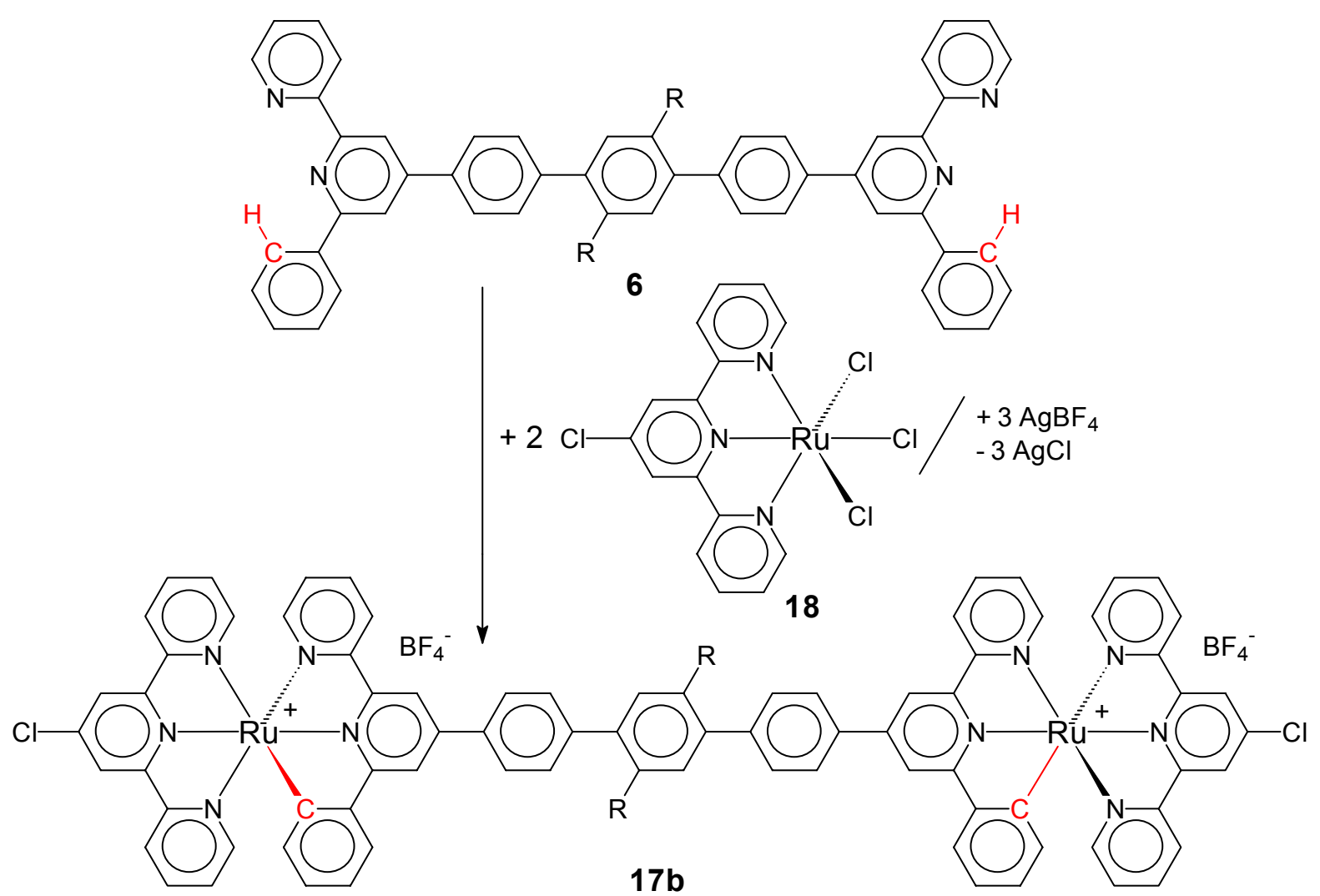

Scheme 8. Model reactions performed in order to optimize the reaction conditions leading to coordination polymers 7

The dinuclear model compound $\mathbf{1 7 b}$ was proven to be a valuable reference compound for the profound NMR-spectroscopic end-group analysis of polymers 7. Depending on the pre-treatment of the polymer molecules to be analyzed, end groups like $\mathbf{F}-\mathbf{H}$ can be expected (Fig. 9). Their unambiguous identification and quantitative evaluation via ${ }^{1} \mathrm{H}$ NMR end-group analysis is essential for estimating at least roughly the achieved values of $P_{\mathrm{n}}$ because most of the conventional methods available for the determination of the molar masses like osmometry, size-exclusion chromatography or light scattering can hardly be applied in the case of the intensely colored polyelectrolytes 7.
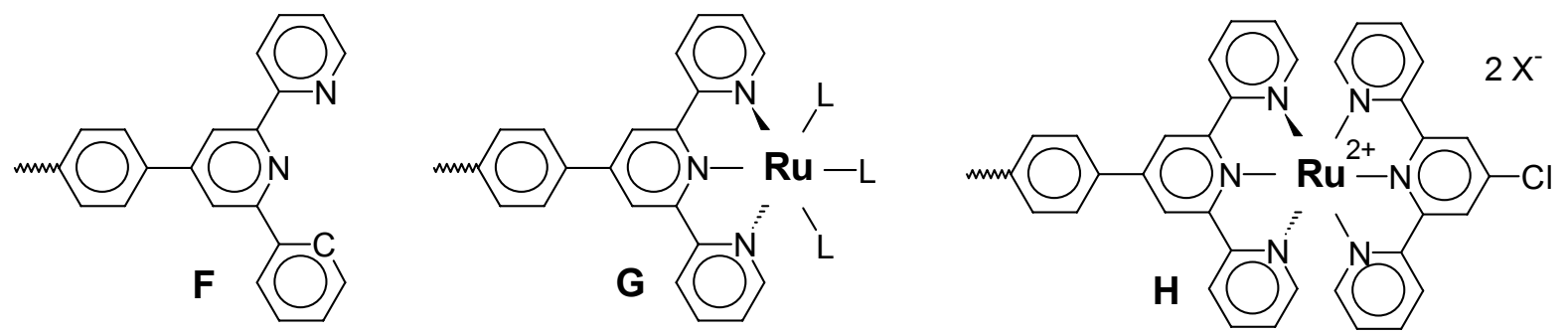

Fig. 9. Possible chain end groups of polymers 7 
For chain-terminus $\mathbf{F}$, which is a free phenylbipyridine moiety, ligand monomer $\mathbf{6}$ is the appropriate model compound. Its ${ }^{1} \mathrm{H}$ and ${ }^{13} \mathrm{C}$ NMR spectra are shown in Figs. $2 \mathrm{~B}$ and $3 \mathrm{~B}$, respectively. A more problematical end group is structure $\mathbf{G}$ where a ruthenium(III) species represents the chain terminus. In this case, no characteristic absorptions were expected in the NMR spectra. Thus, quantitative evaluation is probably impossible. Therefore, prior to the end-group analysis of polymers 7 , all chain termini $\mathbf{G}$ have to be converted into end groups $\mathbf{H}$ via reaction with 4 '-chloro$2,2^{\prime}: 6^{\prime}, 2^{\prime \prime}$-terpyridine 16 (Scheme 10). As one can see now, complex 17b is indeed a highly appropriate model for the formed end groups $\mathbf{H}$.

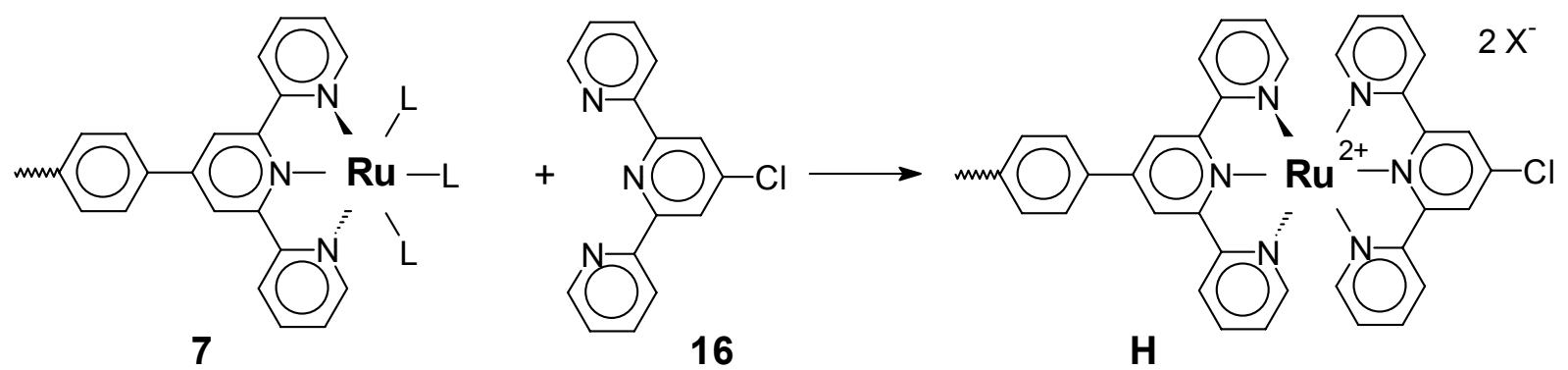

Scheme 10. Conversion of chain terminus $\mathbf{G}$ to give an end group $\mathbf{H}$ readily detectable using NMR spectroscopy

To conclude, the experiments discussed above clearly demonstrate that both steps of route $\mathrm{C}$ shown in Scheme 3 should be possible with sufficient yields and in sufficient homogeneity.

\section{Polymer synthesis}

In a typical polymerization experiment according to Scheme 3, one equivalent of activated metal monomer $\mathbf{8}^{*}$ was dissolved in DMAc and then added over a period of several hours - using a syringe pump - to the heated and vigorously stirred solution of 1 equiv. of ligand monomer $\mathbf{6}$ which was also dissolved in DMAc. After heating the mixture for a further 2 days, the resulting product was precipitated in nearly quantitative yields as a dark violet, fibrous material by pouring the whole reaction mixture into water. The isolated material formed a brittle film which readily and completely redissolved in DMAc or DMSO. Its constitution could therefore be analyzed using ${ }^{1} \mathrm{H}$ and ${ }^{13} \mathrm{C}$ NMR spectroscopy.

In our first polymerization experiments we either used a slight excess of ligand monomer 6, or applied a metal monomer 8 that contained $10 \% \mathrm{RuCl}_{3} \cdot 3 \mathrm{H}_{2} \mathrm{O}, 3$. This was done to obtain polymers of moderate chain length which should guarantee sufficient solubility and thus readily resolved NMR spectra required for the full constitutional analysis.

Fig. 10A shows the ${ }^{1} \mathrm{H}$ NMR spectrum of a polymer 7 that was prepared using a metal monomer 8 that contained some 3 . Based on the data obtained from the above model compounds it seemed obvious that all intense absorptions observed in this spectrum correspond to the protons of the inner-chain repeating units of a constitutionally homogeneous polymer 7 . The corresponding ${ }^{13} \mathrm{C} \mathrm{NMR}$ spectrum also supported this interpretation. However, some additional signals of minor intensity are also detectable. These absorptions may be due either to open ligand end groups like F or end groups $\mathbf{G}$ where ruthenium(III) forms the chain terminus. While the former 
case would point towards incomplete conversion, the latter case would be the expected result because of the presence of $\mathbf{3}$ in monomer $\mathbf{8}$.

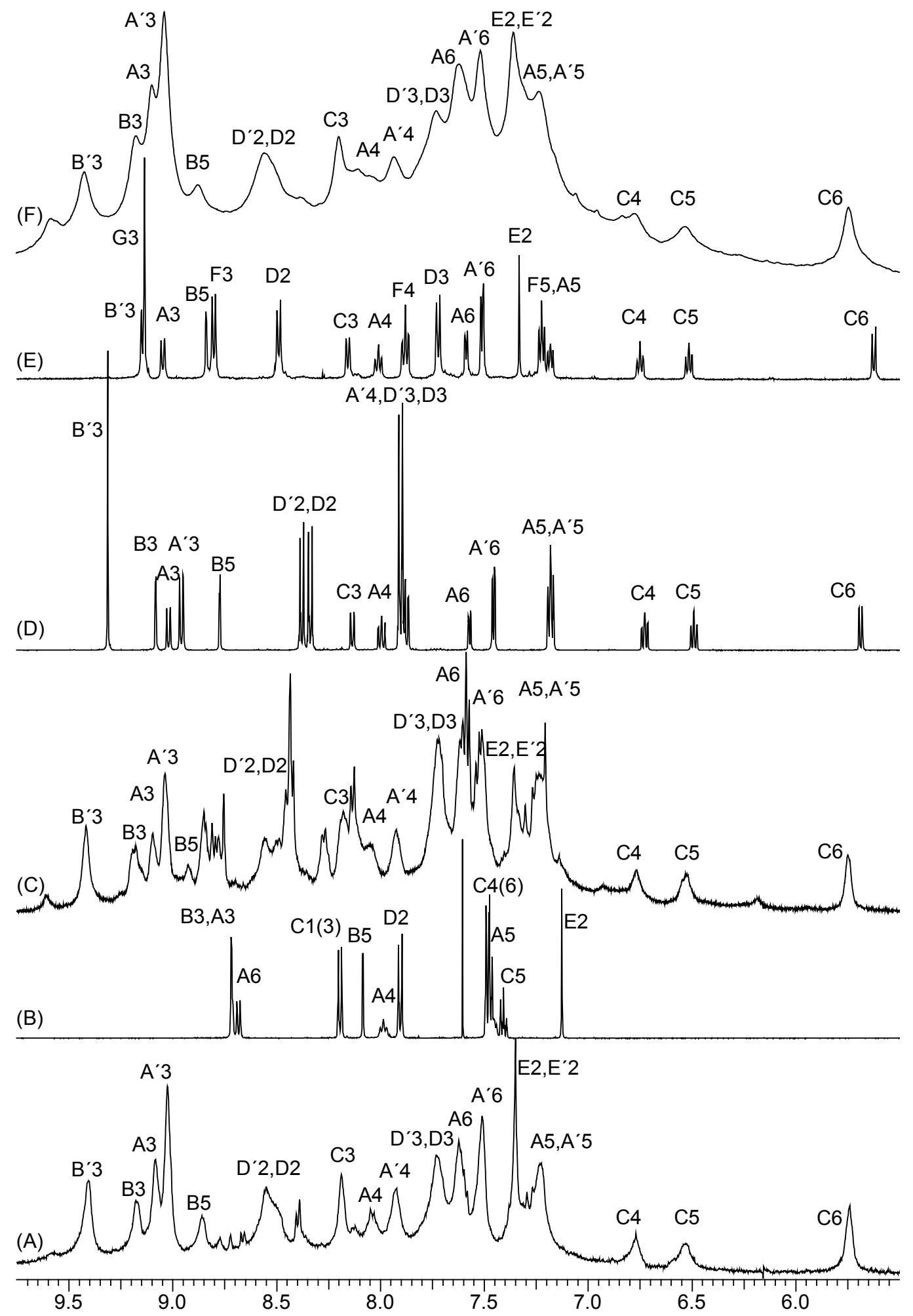

Fig. 10. ${ }^{1} \mathrm{H}$ NMR spectra of $(\mathrm{A})$ an oligomeric complex $7\left(P_{\mathrm{n}} \approx 10\right),(\mathrm{B})$ ligand monomer 6, (C) a very low-molecular-weight sample of $7\left(P_{\mathrm{n}}<4\right)$, (D) mononuclear model complex 15b, $(E)$ dinuclear model complex 17b, and $(F)$ of the high-molecularweight polymer 7, recorded in DMSO- $d_{6}$ solution at room temperature. Absorptions are assigned according to the numbering given in Schemes 4, 6 and 7 
In order to prove that the observed small absorptions are indeed due to the metal termini $\mathbf{G}$, and do not correspond to open ligand end groups $\mathbf{F}$, we compared the small absorptions in Fig. 10A with those of ligand monomer $\mathbf{6}$, dissolved in the same solvent (Fig. 10B). It becomes evident that the absorptions of the ligand monomer are different from those assigned by asterisks in Fig. 10A. Hence, we concluded that a quantitative conversion of the ligand monomers was achieved under the selected reaction conditions.

In the next step, we had to prove that the mentioned small absorptions found in Fig. $10 \mathrm{~A}$ are due to the metal-termini $\mathbf{G}$, and not to constitutional irregularities within the chains like $\mathbf{C}$ - $\mathbf{E}$. In order to clarify this point, further polymers 7 were prepared using metal monomers 8 which contained even larger amounts of $\mathrm{RuCl}_{3} \cdot 3 \mathrm{H}_{2} \mathrm{O}, 3$ (up to $50 \%$ ). Fig. $10 \mathrm{C}$ displays the ${ }^{1} \mathrm{H}$ NMR spectrum of one of the materials obtained in this manner. It becomes clear that all those absorptions which we assigned to end groups in Fig. 10A are much more intensive now. Moreover, there are no further absorptions detectable that might correspond to defects within the resulting polymer. Hence, the resulting polymers are obviously of low molecular weight but constitutionally highly regular.

Based on this information, we were able to assign the intensive but broad and unstructured absorptions to the protons of the inner-chain repeating units of polymer 7. For this purpose, we took advantage of the ${ }^{1} \mathrm{H}$ NMR spectra of the mono- and dinuclear model complexes $15 \mathrm{~b}$ and $\mathbf{1 7 b}$, respectively. The resulting full signal assignment is shown in Fig. 10A, C and F.

Finally, we also tried to prepare really high-molecular-weight polymers 7 . This proved to be possible either by using metal monomers 8 which do not contain any excess of 3 , or by a subsequent conversion of the preformed oligomeric materials 7 like that described above with adequate amounts of ligand monomer 2 or $\mathbf{6}$. In the NMR spectra of the polymers obtained in these two manners, no end-group absorptions are detectable any more, nor further small unidentified signals that might correspond to defects within the polymer chains (Fig. 10F).

All together, these experiments clearly demonstrate that the amount of chain termini present in polymers 7 is in fact below the limits of accuracy of the ${ }^{1} \mathrm{H}$ NMR method. Moreover, formation of cyclic oligomers which could also explain the lack of end group absorptions can be excluded here because of the rodlike shape of the polymers. Therefore, we conclude that high-molecular-weight polymers 7 are available according to Scheme 3 when exactly equimolar amounts of pure comonomers 6 and $\mathbf{8}^{*}$ are used. Considering the very broad absorptions and the general limits of the NMR method, we estimate average degrees of polymerization achieved in our best polymers 7 to be $P_{\mathrm{n}(\mathrm{NMR})} \geq 20$. This assessment is in full agreement with the results reported previously for coordination polymers 1 [19].

\section{UV-vis spectroscopy}

In order to find out the consequences of $(i)$ the introduction of a ruthenium-carbon bond into the octahedral ruthenium(II) complexes and of (ii) the incorporation of the $\left[\mathrm{RuN}_{5} \mathrm{C}\right]^{+}$motifs into a polymeric chain, a series of UV-vis spectra was recorded. In particular, we were interested to see whether there is any evidence of electronic interaction between the individual metal complex centers along the polymer chains 7 . Fig. 11 displays the UV-vis absorption spectra of three $\left[\mathrm{RuN}_{5} \mathrm{C}\right]^{+}$motifs, i.e., of the dinuclear model complex $17 \mathrm{a}(\mathrm{C}$; see Scheme 6$)$, of the corresponding mononuclear 
model complex 15b (D; see Scheme 7), and of a high-molecular-weight sample of polymer 7 (E; see Scheme 3) in DMSO solution. For comparison purposes, moreover, the $\left[\mathrm{RuN}_{6}\right]^{2+}$ motifs $\left[\mathrm{Ru}\left(p-\mathrm{Brph}-\mathrm{tpy}_{2}\right)_{2}\right]\left(\mathrm{PF}_{6}\right)_{2} \mathbf{1 5}^{15 a}$ (A; see Scheme 5) and polymer 1 (B; see Scheme 1) are shown as well.

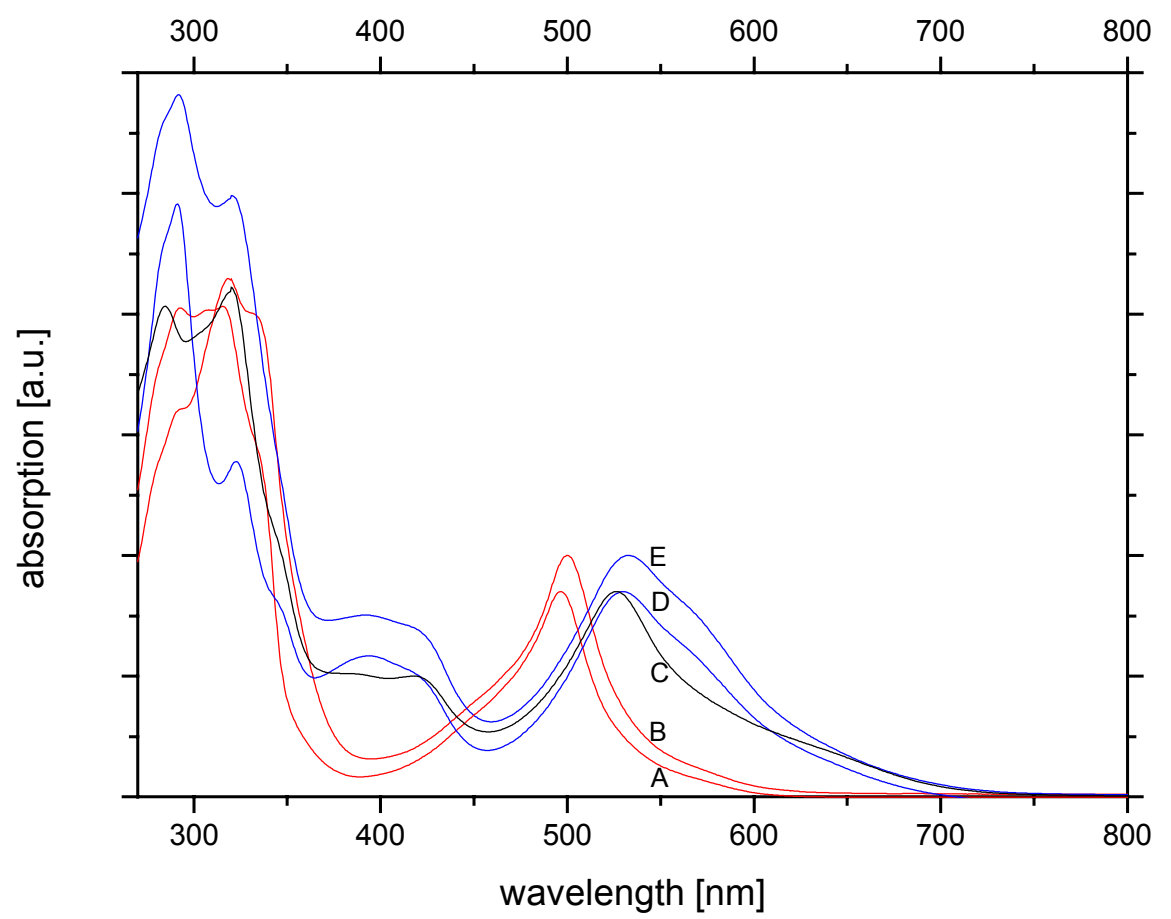

Fig. 11. UV-vis absorption spectra of $\left[R u(p-B r P h t p y)_{2}\right]\left(P_{6}\right)_{2}$ 15a $(A$; see Scheme 5), of polymer 1 ( $B$; see Scheme 1), of the dinuclear model complex 17a $(C$; see Scheme 6), of the corresponding mononuclear model complex $15 \mathrm{~b}$ (D; see Scheme 7), and of a high-molecular-weight sample of polymer 7 (E; see Scheme 3) in DMSO solution

In all these spectra, intense absorptions are observed at wavelengths below $\lambda=380$ $\mathrm{nm}$ which can be assigned to ligand-centered (LC) $\pi^{*} \leftarrow \pi$ transitions within the pyridine and phenyl moieties. Differences in this region between the spectra of the monomeric, dimeric and polymeric complexes are rather negligible and can be explained on the basis of the different constitution of the respective ligand moieties. Thus no systematic shift of these absorptions is observed as a function of the length of the chains under consideration. This statement is tantamount to the lack of $\pi$ electron conjugation along the chains and in particular across the transition-metal complexes.

Above $\lambda \approx 380 \mathrm{~nm}$, absorptions are observed which can be assigned to the metal-toligand charge-transfer (MLCT) transitions [40,50,51]. A very broad absorption is found in spectra $C-E$ at $\lambda \approx 530 \mathrm{~nm}$ which is interpreted as MLCT transition involving the LUMO (lowest unoccupied molecular orbital) of the pyridine-based ligands. This assignment seems to be reliable because a similar absorption was found in the corresponding $\left[\mathrm{RuN}_{6}\right]^{2+}$ complexes $15 \mathrm{a}$ (spectrum A) and polymer 1 (spectrum B). However, upon comparison of the spectra shown in Fig. 11 it becomes evident that this MLCT transition appears at a longer wavelength in the case of the $\left[\mathrm{RuN}_{5} \mathrm{C}\right]^{+}$ motifs which might be due to the ruthenium-carbon bond which increases the electron density at the ruthenium. 
Moreover, a second broad absorption is found in the MLCT range in spectra $C$ - E which appears at $\lambda \approx 400 \mathrm{~nm}$. This absorption has no counterpart in spectra $A$ and $B$ of the $\left[\mathrm{RuN}_{6}\right]^{2+}$ species. Therefore, we assign this absorption to a further MLCT transition, corresponding to the charge transfer from the ruthenium to the LUMO of the phenyl-based ligand. The shorter wavelength of this latter transition compared to the MLCT band discussed above is due to the fact that the level of the LUMO for the cyclometallated (anionic) ligand is higher in energy than that of an isoelectronic but neutral pyridine-based ligand [50].

Moreover, it is clearly evident that there is an appreciable absorbance in the spectrum of polymer 7 (Fig. 11E) even at wavelengths above $\lambda=600 \mathrm{~nm}$. This might be interpreted as the consequence of a certain electron delocalization along the polymer chains. However, the spectra of the dinuclear as well as mononuclear complexes $17 \mathrm{~b}$ and $\mathbf{1 5 b}$, respectively, show the same characteristics. Hence, this broadening of the absorption in Fig. 11E cannot be interpreted as a consequence of the incorporation of the $\left[\mathrm{RuN}_{5} \mathrm{C}\right]^{+}$motifs into a polymer chain but must have other reasons which we have been unable to identify so far.

This interpretation is in agreement with theoretical arguments as well as with the results of measurements on related complexes. We therefore conclude that there is no intramolecular electronic interaction observable by UV-vis spectroscopy between the ruthenium(II) centers of the polynuclear complexes under investigation here. The polymers 7 can therefore be considered as sequences of electronically nearly independent ruthenium(II) complexes.

\section{Conclusions and outlook}

An efficient synthetic procedure is presented which allows the preparation of rodlike ruthenium(II) coordination polymers 7 whose main chains are held together by pseudo-octahedral ruthenium(II) complexes in which five ligands are nitrogen and one ligand is carbon. In the first step of polymer synthesis, the bis-tridentate ligand 4,4 "-bis[4'-(2,2':6',2"-terpyridine)]-2',5'-dihexyl-p-terphenyl is treated with two equivalents of ruthenium(III) chloride. The resulting dinuclear 'metal-monomer' can be converted - under optimized conditions and after appropriate activation - with equimolar amounts of 4,4"-bis[4'-(6'-phenyl-2,2'-bipyridine)]-2',5'-dihexyl-p-terphenyl. The homogeneous constitution of the readily soluble polymers is proven, and their degrees of polycondensation are roughly estimated to be $P_{\mathrm{n}} \geq 20$, using ${ }^{1} \mathrm{H}$ and ${ }^{13} \mathrm{C}$ NMR spectroscopy. The UV-vis absorption spectra show that the polymers behave like chains of independent metal complexes. Presently, we are trying to analyze the molar masses of 7 more precisely, and are attempting to determine the persistence length of the chains to estimate the extent by which the octahedral metal complexes lower the rigidity of the chains. Moreover, the spectroscopic and electrochemical behavior of polymers 7 is under further investigation.

\section{Experimental part}

\section{Materials}

All chemicals and solvents were purchased from Acros, Aldrich, Fluka, Strem and Lancaster Chemical Co. and used without further purification. Benzene-1,4-diboronic acid 5 was prepared according to ref. [31]. 1-(2-Pyridacyl)pyridinium iodide 10 was prepared according to ref. [52], 4,4"-bis(2,2':6':2"-terpyridine)-2',5'-dihexyl-p-terphenyl 
2 according to ref. [19], and p-bromobenzylacetophenone 12b was synthesized according to ref. [54]. All reactions were carried out under an atmosphere of nitrogen.

\section{Methods}

NMR spectra were recorded using a Bruker Avance 500 NMR spectrometer working at $500 \mathrm{MHz}\left({ }^{1} \mathrm{H}\right.$ NMR) and $125 \mathrm{MHz}\left({ }^{13} \mathrm{C}\right.$ NMR). The signal assignment in the ${ }^{1} \mathrm{H}$ and ${ }^{13} \mathrm{C}$ NMR spectra was made according to the numbering given for the protons and carbons, respectively, of selected compounds shown in Schemes 4, 6 and 7. UV-vis measurements were carried out using an Analytik Jena AG Specord 200 photospectrometer. Elemental analyses were performed using a Perkin Elmer 240-B elemental analyzer; double focused mass spectra were recorded using a MAT 311A instrument from Varian: $\mathrm{EI}=$ electron impact; $\mathrm{FD}=$ field desorption; $\mathrm{ESI}=$ electron spray ionization. Maldi spectra were recorded using a MALDI-TOF IV instrument from Shimadzu / Kratos.

\section{4-Bromo-2-cinnamoylpyridine 12a [53]}

p-Bromobenzaldehyde 11 (10.69 g, $0.0578 \mathrm{~mol}$ ) was dissolved in warm methanol (16 $\mathrm{mL})$. This solution was added slowly to aqueous $\mathrm{NaOH}(10 \% \mathrm{w} / \mathrm{w} ; 46.7 \mathrm{~g}, 1.153 \mathrm{~mol})$. The resulting white suspension was cooled down $\left(5^{\circ} \mathrm{C}\right)$. With vigorous stirring, 2acetylpyridine 9a $(7.00 \mathrm{~g}, 0.0578 \mathrm{~mol})$ was added dropwise within $30 \mathrm{~min}$ to the cooled suspension, and a tacky precipitate was produced. After $30 \mathrm{~min}$, water (400 $\mathrm{mL}$ ) was added, and stirring continued at room temperature for $1 \mathrm{~h}$. The resulting yellow precipitate was collected in a Büchner funnel and washed with methanol $(3 \mathrm{x}$ $40 \mathrm{~mL}$ ). The obtained organic solutions were stirred for a further $1 \mathrm{~h}$ to complete the conversion. The resulting solid was filtered off, and the combined solid products were washed with water $(100 \mathrm{~mL})$ and methanol $(20 \mathrm{~mL})$. The crude product in sufficient purity for the following reactions was obtained in amounts of $15.5 \mathrm{~g} \mathrm{(93 \% ).} \mathrm{It} \mathrm{may} \mathrm{be}$

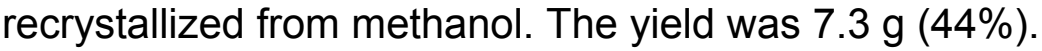

${ }^{1} \mathrm{H}$ NMR $\left(\mathrm{CDCl}_{3}\right): \delta=7.53\left(\mathrm{~m}, 5 \mathrm{H}, \mathrm{H}^{5}, \mathrm{H}^{11}, \mathrm{H}^{12}\right), 7.83\left(\mathrm{~d}, 1 \mathrm{H}, \mathrm{H}^{8}\right), 7.86\left(\mathrm{dt}, 1 \mathrm{H}, \mathrm{H}^{4}\right)$, $8.17\left(\mathrm{dt}, 1 \mathrm{H}, \mathrm{H}^{3}\right), 8.28\left(\mathrm{~d}, 1 \mathrm{H}, \mathrm{H}^{9}\right), 8.72\left(1 \mathrm{H}, \mathrm{H}^{6}\right)$.

${ }^{13} \mathrm{C}$ NMR $\left(\mathrm{CDCl}_{3}\right): \delta=121.34\left(\mathrm{~d}, \mathrm{C}^{5}\right), 122.96\left(\mathrm{~d}, \mathrm{C}^{3}\right), 124.80\left(\mathrm{~s}, \mathrm{C}^{13}\right), 127.01\left(\mathrm{~d}, \mathrm{C}^{8}\right)$, $130.12\left(\mathrm{~d}, \mathrm{C}^{11}\right), 132.07\left(\mathrm{~d}, \mathrm{C}^{12}\right), 133.99\left(\mathrm{~s}, \mathrm{C}^{10}\right), 137.15\left(\mathrm{~d}, \mathrm{C}^{4}\right), 143.26\left(\mathrm{~d}, \mathrm{C}^{9}\right)$, $148.72\left(\mathrm{~d}, \mathrm{C}^{6}\right), 153.84\left(\mathrm{~s}, \mathrm{C}^{2}\right), 189.10\left(\mathrm{~s}, \mathrm{C}^{7}\right)$.

\section{4'-(p-Bromophenyl)-6'-phenyl-2,2'-bipyridine 13b}

A mixture of $12 \mathrm{~b}$ (4.00 g, $0.0139 \mathrm{~mol}), 1$-(2-pyridacyl)pyridinium iodide 10 (4.54 g, $0.0139 \mathrm{~mol})$, ammonium acetate $(28.0 \mathrm{~g}, 0.363 \mathrm{~mol})$ and acetic acid $(28 \mathrm{~mL})$ was stirred and slowly heated, within approx. $30 \mathrm{~min}$, to $180^{\circ} \mathrm{C}$ under an atmosphere of nitrogen. Stirring and heating was continued for $5 \mathrm{~h}$. The resulting dark homogeneous solution was allowed to cool down to room temperature. The resulting solid was removed by filtration, dried and recrystallized from ethanol $(2 \times 150 \mathrm{~mL})$. Finally, the product was dried in vacuo $\left(\mathrm{P}_{4} \mathrm{O}_{10}\right)$. The yield was $4.1 \mathrm{~g}(76 \%)$.

${ }^{1} \mathrm{H} \mathrm{NMR}\left(\mathrm{CDCl}_{3}\right): \delta=7.32\left(\mathrm{~m}, 1 \mathrm{H}, \mathrm{H}^{\mathrm{A} 5}\right), 7.44\left(\mathrm{t}, 1 \mathrm{H}, \mathrm{H}^{\mathrm{C} 5}\right), 7.51\left(\mathrm{t}, 2 \mathrm{H}, \mathrm{HC}^{4,6}\right), 7.61(\mathrm{dt}$, $\left.2 \mathrm{H}, \mathrm{H}^{\mathrm{D} 2}\right), 7.65\left(\mathrm{dt}, 2 \mathrm{H}, \mathrm{H}^{\mathrm{D} 3}\right), 7.84\left(\mathrm{td}, 1 \mathrm{H}, \mathrm{H}^{\mathrm{A} 4}\right), 7.89\left(\mathrm{~d}, 1 \mathrm{H}, \mathrm{H}^{\mathrm{B} 5}\right), 8.17\left(\mathrm{t}, 2 \mathrm{H}, \mathrm{H}^{\mathrm{C} 1,3}\right)$, $8.60\left(\mathrm{~d}, 1 \mathrm{H}, \mathrm{H}^{\mathrm{B} 3}\right), 8.66\left(\mathrm{~d}, 1 \mathrm{H}, \mathrm{H}^{\mathrm{A} 3}\right), 8.69\left(\mathrm{~d}, 1 \mathrm{H}, \mathrm{H}^{\mathrm{A} 6}\right)$. 
${ }^{13} \mathrm{C}$ NMR $\left(\mathrm{CDCl}_{3}\right): \delta=117.89\left(\mathrm{~d}, \mathrm{C}^{\mathrm{B} 3}\right), 118.05\left(\mathrm{~d}, \mathrm{C}^{\mathrm{B} 5}\right), 121.58\left(\mathrm{~d}, \mathrm{C}^{\mathrm{A} 3}\right), 123.42(\mathrm{~s}$, $\left.\mathrm{C}^{\mathrm{D} 4}\right), 123.88\left(\mathrm{~d}, \mathrm{C}^{\mathrm{A} 5}\right), 127.04\left(\mathrm{~d}, \mathrm{C}^{\mathrm{C} 1,3}\right), 128.73\left(\mathrm{~d}, 2 \mathrm{C}, \mathrm{C}^{\mathrm{C} 4,6}\right), 128.76\left(\mathrm{~d}, 2 \mathrm{C}, \mathrm{C}^{\mathrm{D} 2}\right)$, $129.17\left(\mathrm{~d}, \mathrm{C}^{\mathrm{C} 5}\right), 132.15\left(\mathrm{~d}, 2 \mathrm{C}, \mathrm{C}^{\mathrm{D} 3}\right), 137.02\left(\mathrm{~d}, \mathrm{C}^{\mathrm{A} 4}\right), 137.59\left(\mathrm{~s}, \mathrm{C}^{\mathrm{D} 2}\right), 139.22\left(\mathrm{~s}, \mathrm{C}^{\mathrm{C} 2}\right)$, $148.83\left(\mathrm{~d}, \mathrm{C}^{\mathrm{A} 6}\right), 148.96\left(\mathrm{~s}, \mathrm{C}^{\mathrm{B} 4}\right), 155.99\left(\mathrm{~s}, \mathrm{C}^{\mathrm{A} 2}\right), 156.18\left(\mathrm{~s}, \mathrm{C}^{\mathrm{B} 2}\right), 157.29\left(\mathrm{~s}, \mathrm{C}^{\mathrm{B} 6}\right)$.

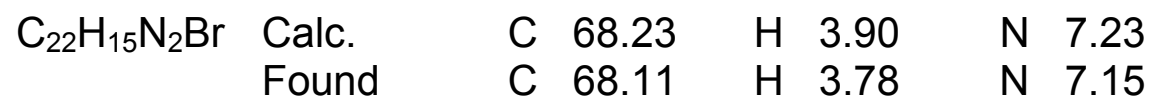

$\mathrm{MS}(\mathrm{EI}) \mathrm{C}_{62} \mathrm{H}_{58} \mathrm{~N}_{4}: m / z=386\left(\mathrm{M}^{+}\right)$.

\section{4,4"-Bis(6'-phenyl-2,2'-bipyridine)-2',5'-di-n-hexyl-p-terphenyl 6}

4'-(p-Bromophenyl)-6'-phenyl-2,2'-bipyridine 13b (0.7001 g; $1.809 \mathrm{mmol}), 2,5-\mathrm{di}-\mathrm{n}$ hexylbenzene-1,4-diboronic acid $5(0.3020 \mathrm{~g}, 0.899 \mathrm{mmol})$ and $\left[\mathrm{Pd}\left(\mathrm{PPh}_{3}\right)_{4}\right](0.015 \mathrm{~g}$, $0.0013 \mathrm{mmol}, 0.72 \mathrm{~mol}-\%$ with respect to $13 \mathrm{~b}$ ) were refluxed and vigorously stirred for $24 \mathrm{~h}$ in the heterogeneous system of toluene $\left(35.0 \mathrm{~mL}\right.$ ) and aqueous $\mathrm{Na}_{2} \mathrm{CO}_{3}$ (35 $\mathrm{mL}, 1 \mathrm{M})$. At room temperature, water $(100 \mathrm{~mL})$ was added, and the resulting mixture was extracted with $\mathrm{CHCl}_{3}(3 \times 100 \mathrm{~mL})$. The combined organic layers were dried $\left(\mathrm{Na}_{2} \mathrm{SO}_{4}\right)$, the solvent was removed, and the obtained solid was recrystallized from a mixture of ethanol and chloroform (9:1; v/v). Yield (after recrystallization): $0.5178 \mathrm{~g}$ $(66.7 \%)$

${ }^{1} \mathrm{H}$ NMR $\left(\mathrm{CDCl}_{3} / \mathrm{DMSO}_{-} \mathrm{d}_{6} 7 / 1\right): \delta=0.82\left(\mathrm{t}, 6 \mathrm{H}, \mathrm{CH}_{3}\right), 1.21\left(\mathrm{~m}, 12 \mathrm{H}, \mathrm{CH}_{2}\right), 1.54(\mathrm{~m}$, $\left.4 \mathrm{H}, \beta-\mathrm{CH}_{2}\right), 2.67\left(\mathrm{t}, 4 \mathrm{H}, \alpha-\mathrm{CH}_{2}\right), 7.21\left(\mathrm{~s}, 2 \mathrm{H}, \mathrm{H}^{\mathrm{E} 2}\right), 7.49\left(\mathrm{~m}, 2 \mathrm{H}, \mathrm{H}^{\mathrm{C} 5}\right), 7.55(\mathrm{~m}, 10 \mathrm{H}$, $\left.\mathrm{H}^{\mathrm{A} 5, \mathrm{C} 4, \mathrm{D} 3}\right), 7.98\left(\mathrm{~d}, 4 \mathrm{H}, \mathrm{H}^{\mathrm{D} 2}\right), 8.07\left(\mathrm{t}, 2 \mathrm{H}, \mathrm{H}^{\mathrm{A} 4}\right), 8.07\left(\mathrm{t}, 2 \mathrm{H}, \mathrm{H}^{\mathrm{A} 4}\right), 8.17\left(\mathrm{~s}, 2 \mathrm{H}, \mathrm{H}^{\mathrm{B} 5}\right), 8.28$ $\left(\mathrm{d}, 4 \mathrm{H}, \mathrm{H}^{\mathrm{C} 1,3}\right), 8.76\left(\mathrm{~d}, 2 \mathrm{H}, \mathrm{H}^{\mathrm{A} 3}\right), 8.80\left(\mathrm{~m}, 4 \mathrm{H}, \mathrm{H}^{\mathrm{B} 3, \mathrm{~A} 6}\right)$.

${ }^{13} \mathrm{C}$ NMR $\left(\mathrm{CDCl}_{3} / \mathrm{DMSO}-d_{6} 7 / 1\right): \delta=13.97\left(\mathrm{q}, \mathrm{CH}_{3}\right), 22.27,28.95,31.20,31.31,32.49$ $\left(5 \mathrm{t}, \mathrm{CH}_{2}\right), 117.61\left(\mathrm{~d}, \mathrm{C}^{\mathrm{B} 3}\right), 118.54\left(\mathrm{~d}, \mathrm{C}^{\mathrm{B} 5}\right), 124.42\left(\mathrm{~d}, \mathrm{C}^{\mathrm{A} 3}\right), 126.85\left(\mathrm{~d}, \mathrm{C}^{\mathrm{A} 5}\right), 127.02(\mathrm{~d}$, $\left.\mathrm{C}^{\mathrm{D} 2, \mathrm{C} 13}\right), 128.72\left(\mathrm{~d}, \mathrm{C}^{\mathrm{C} 4,6}\right), 129.26\left(\mathrm{~d}, \mathrm{C}^{\mathrm{C} 5}\right), 129.95\left(\mathrm{~d}, \mathrm{C}^{\mathrm{D} 3}\right), 130.79\left(\mathrm{~d}, \mathrm{C}^{\mathrm{E} 2}\right), 136.42$ $\left(\mathrm{s}, \mathrm{C}^{\mathrm{D} 1}\right), 137.41\left(\mathrm{~s}, \mathrm{C}^{\mathrm{E} 3}\right), 138.68\left(\mathrm{~s}, \mathrm{C}^{\mathrm{C} 2}\right), 138.86\left(\mathrm{~d}, \mathrm{C}^{\mathrm{A4}}\right), 140.11\left(\mathrm{~s}, \mathrm{C}^{\mathrm{E} 1}\right), 142.87(\mathrm{~s}$, $\left.\mathrm{C}^{\mathrm{D} 4}\right), 147.75\left(\mathrm{~d}, \mathrm{C}^{\mathrm{A} 6}\right), 149.97\left(\mathrm{~s}, \mathrm{C}^{\mathrm{B} 4}\right), 154.47\left(\mathrm{~s}, \mathrm{C}^{\mathrm{A} 2}\right), 154.87\left(\mathrm{~s}, \mathrm{C}^{\mathrm{B} 2}\right), 157.20\left(\mathrm{~s}, \mathrm{C}^{\mathrm{B} 6}\right)$.

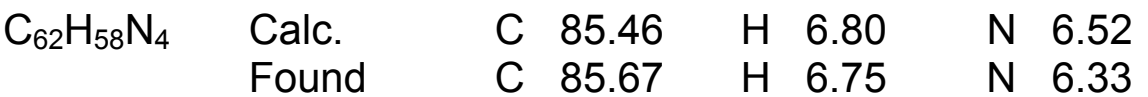

$\mathrm{MS}(\mathrm{FD}) \mathrm{C}_{62} \mathrm{H}_{58} \mathrm{~N}_{4}: m / z=859\left(\mathrm{M}^{+}\right)$.

\section{4'-Chloro-2,2':6',2"-terpyridineruthenium(III) chloride 18 [55]}

4'-Chloro-2,2':6',2"-terpyridine 16 (296.9 mg, $1.1206 \mathrm{~mol})$ was dissolved in dry ethanol $(150 \mathrm{~mL})$ under an atmosphere of nitrogen and refluxed. Within $15 \mathrm{~min}$, a solution of $\mathrm{RuCl}_{3} \cdot 3 \mathrm{H}_{2} \mathrm{O}, 3(289.8 \mathrm{mg}, 1.108 \mathrm{~mol})$ in dry ethanol $(60 \mathrm{~mL})$ was added dropwise. After stirring for a further $1 \mathrm{~h}$ under reflux, the mixture was allowed to cool down to room temperature, and the resulting solid was isolated by filtration. The solid was washed with ethanol $(2 \times 50 \mathrm{~mL})$ and diethyl ether $(50 \mathrm{~mL})$ and dried in vacuo $\left(\mathrm{P}_{4} \mathrm{O}_{10}\right)$. The yield was $467.3 \mathrm{mg}(96.3 \%)$.

\section{4'-(p-Bromophenyl)-2,2':6',2"-terpyridineruthenium(III) chloride 14a}

4'-(p-Bromophenyl)-2,2':6',2"-terpyridine 13a (776.5 mg, $2.000 \mathrm{~mol}$ ) was dissolved in dry ethanol $\left(300 \mathrm{~mL}\right.$ ) and refluxed. Within $30 \mathrm{~min}$, a solution of $\mathrm{RuCl}_{3} \cdot 3 \mathrm{H}_{2} \mathrm{O}, 3$ $(520.0 \mathrm{mg}, 1.989 \mathrm{~mol})$ in dry ethanol $(100 \mathrm{~mL})$ was added dropwise. After stirring for 
a further $1 \mathrm{~h}$ under reflux, the mixture was allowed to cool down to room temperature, and the resulting solid was isolated by filtration. The solid was washed with ethanol (2 $x 50 \mathrm{~mL})$ and diethyl ether $(50 \mathrm{~mL})$ and dried in vacuo $\left(\mathrm{P}_{4} \mathrm{O}_{10}\right)$. The yield was 1012.7 $\mathrm{mg}(85.5 \%)$.

MS (MALDI): $560\left(\mathrm{C}_{21} \mathrm{H}_{14} \mathrm{~N}_{3} \mathrm{BrRuCl}_{2}^{+}\right) ; 525\left(\mathrm{C}_{21} \mathrm{H}_{14} \mathrm{~N}_{3} \mathrm{BrRuCl}^{+}\right) ; 488\left(\mathrm{C}_{21} \mathrm{H}_{14} \mathrm{~N}_{3} \mathrm{BrRu}^{+}\right)$.

UV/VIS: (dichloroethane, $\mathrm{nm}$ ): 287.5 (strong), 311.5 (strong), 422.5 (shoulder), 491.0 (mid-strong), 530.5 (shoulder).

\section{4,4"-Bis(2, 2':6', 2"-terpyridine)-2', 5'-di-n-hexyl-p-terphenyl-bis-ruthenium(III) chloride 8}

$\mathrm{RuCl}_{3} \cdot 3 \mathrm{H}_{2} \mathrm{O}, 3$ (546.4 mg, $2.090 \mathrm{mmol}$ ) was dissolved in hot, dry n-butanol (50 mL). A solution of 4,4"-bis(2,2':6',2"-terpyridine)-2',5'-di-n-hexyl-p-terphenyl 2 (450.6 mg, $0.5226 \mathrm{mmol})$ in dry n-butanol $(550 \mathrm{~mL})$ was added quickly. After stirring for a further 15 min under reflux, the mixture was allowed to cool down to room temperature within approx. $1 \mathrm{~h}$, and the resulting solid was isolated by filtration. The solid was washed with ethanol (2 x $50 \mathrm{~mL})$ and diethyl ether $(50 \mathrm{~mL})$ and dried in vacuo $\left(\mathrm{P}_{4} \mathrm{O}_{10}\right)$. The yield was $615.7 \mathrm{mg}(92.3 \%)$.

\section{Bis(4'-chloro-2,2':6',2"-terpyridine)ruthenium(II) tetrafluoroborate}

$\mathrm{RuCl}_{3} \cdot 3 \mathrm{H}_{2} \mathrm{O}, 3$ (255.7 mg, $\left.0.9779 \mathrm{mmol}\right), \mathrm{AgBF}_{4}(591.0 \mathrm{mg}, 3.036 \mathrm{mmol}$ ) and acetone $(50 \mathrm{~mL})$ were refluxed for $3 \mathrm{~h}$ under an atmosphere of nitrogen. The resulting solid was separated off, and the obtained solution was concentrated down to dryness. 4'-Chloro-2,2':6',2"-terpyridine (582.8 mg, $2.177 \mathrm{mmol})$ and n-butanol (50 $\mathrm{mL}$ ) were added to the residue, and the resulting mixture was refluxed for a further day. The resulting red precipitate was filtered off and washed (n-butanol). The yield of the dry product was $633.5 \mathrm{mg}\left(78.4 \%\right.$ related to $\left.\mathrm{RuCl}_{3}\right)$. For additional purification, further 4'-chloro-2,2':6',2"-terpyridine (26.6 mg, $0.0994 \mathrm{mmol})$, n-butanol $(25 \mathrm{~mL})$ and water $(12.5 \mathrm{~mL})$ were added to the wet material and heated for a further $24 \mathrm{~h}$. The obtained solid was filtered off, washed (n-butanol) and dried in vacuo $\left(\mathrm{P}_{4} \mathrm{O}_{10}\right)$. The yield was $444.2 \mathrm{mg}(55.0 \%)$.

${ }^{1} \mathrm{H}$ NMR (DMSO- $\left.d_{6}\right): \delta=7.28\left(\mathrm{t}, 4 \mathrm{H}, \mathrm{H}^{\mathrm{F} 5}\right), 7.59\left(\mathrm{~d}, 4 \mathrm{H}, \mathrm{H}^{\mathrm{F} 6}\right), 8.04\left(\mathrm{t}, 4 \mathrm{H}, \mathrm{H}^{\mathrm{F} 4}\right), 8.89(\mathrm{~d}$, $\left.4 \mathrm{H}, \mathrm{H}^{\mathrm{F} 3}\right), 9.34\left(\mathrm{~s}, 4 \mathrm{H}, \mathrm{H}^{\mathrm{G} 3}\right)$.

${ }^{1} \mathrm{H}$ NMR $\left(\mathrm{CD}_{3} \mathrm{CN}\right): \delta=7.19\left(\mathrm{t}, 4 \mathrm{H}, \mathrm{H}^{\mathrm{F} 5}\right), 7.39\left(\mathrm{~d}, 4 \mathrm{H}, \mathrm{H}^{\mathrm{F} 6}\right), 7.94\left(\mathrm{t}, 4 \mathrm{H}, \mathrm{H}^{\mathrm{F} 4}\right), 8.48(\mathrm{~d}$, $\left.4 \mathrm{H}, \mathrm{H}^{\mathrm{F} 3}\right), 8.84\left(\mathrm{~s}, 4 \mathrm{H}, \mathrm{H}^{\mathrm{G} 3}\right)$.

${ }^{13}$ C NMR (DMSO- $\left.d_{6}\right): \delta=123.76\left(d, C^{G 3}\right), 124.52\left(d, C^{F 3}\right), 127.56\left(d, C^{F 5}\right), 137.69(d$, $\left.\mathrm{C}^{\mathrm{F} 4}\right), 141.78\left(\mathrm{~s}, \mathrm{C}^{\mathrm{G} 4}\right), 152.06\left(\mathrm{~d}, \mathrm{C}^{\mathrm{F} 6}\right), 155.31\left(\mathrm{~s}, \mathrm{C}^{\mathrm{G} 2}\right), 156.41\left(\mathrm{~s}, \mathrm{C}^{\mathrm{F} 2}\right)$.

\section{Bis[4'-(p-bromophenyl)-2,2':6',2"-terpyridine]ruthenium(II) tetrafluoroborate 15a}

$\mathrm{RuCl}_{3} \cdot 3 \mathrm{H}_{2} \mathrm{O}, 3$ (172.2 mg, 0.6586 mmol), AgBF 4 (397.4 mg, $2.042 \mathrm{mmol}$ ) and acetone $(55 \mathrm{~mL})$ were refluxed for $3 \mathrm{~h}$. The resulting solid was separated off, and the obtained solution was concentrated down to dryness. 4'-(p-Bromophenyl)-2,2':6',2"terpyridine 13a $(550.1 \mathrm{mg}, 1.4168 \mathrm{mmol})$ and $\mathrm{n}$-butanol $(55 \mathrm{~mL})$ were added to the residue, and the resulting mixture was refluxed for a further $24 \mathrm{~h}$. The resulting red precipitate was filtered off and washed (n-butanol). The yield was $632.1 \mathrm{mg}(91.3 \%)$. For further purification, 4'-( $p$-bromophenyl)-2,2':6',2"-terpyridine (49.3 mg, 0.1270 
$\mathrm{mmol})$ and $\mathrm{n}$-butanol $(50 \mathrm{~mL})$ were added to the material and heated for a further 12 $\mathrm{h}$. The obtained solid was filtered off, washed with $\mathrm{n}$-butanol $(20 \mathrm{~mL})$ and diethyl ether $(20 \mathrm{~mL})$, and dried in vacuo $\left(\mathrm{P}_{4} \mathrm{O}_{10}\right)$. The yield was $571.1 \mathrm{mg}(82.5 \%)$.

${ }^{1} \mathrm{H}$ NMR (DMSO- $\left.d_{6}\right): \delta=7.30\left(\mathrm{t}, 4 \mathrm{H}, \mathrm{H}^{\mathrm{A} 5}\right), 7.57\left(\mathrm{~d}, 4 \mathrm{H}, \mathrm{H}^{\mathrm{A} 6}\right), 8.01\left(\mathrm{~d}, 4 \mathrm{H}, \mathrm{H}^{\mathrm{D} 3}\right), 8.08(\mathrm{t}$, $\left.4 \mathrm{H}, \mathrm{H}^{\mathrm{A} 4}\right), 8.43\left(\mathrm{~d}, 4 \mathrm{H}, \mathrm{H}^{\mathrm{D} 2}\right), 9.11\left(\mathrm{~d}, 4 \mathrm{H}, \mathrm{H}^{\mathrm{A} 3}\right), 9.50\left(\mathrm{~s}, 4 \mathrm{H}, \mathrm{H}^{\mathrm{B} 3}\right)$.

${ }^{13}$ C NMR (DMSO- $\left.d_{6}\right): \delta=120.91\left(\mathrm{~d}, \mathrm{C}^{\mathrm{B} 3}\right), 124.03\left(\mathrm{~s}, \mathrm{C}^{\mathrm{D} 4}\right), 124.77\left(\mathrm{~d}, \mathrm{C}^{\mathrm{A} 3}\right), 127.68(\mathrm{~d}$, $\left.C^{A 5}\right), 129.61\left(d, C^{D 2}\right), 132.26\left(d, C^{D 3}\right), 135.24\left(s, C^{D 1}\right), 137.97\left(d, C^{A 4}\right), 145.58\left(s, C^{B 4}\right)$, $152.13\left(\mathrm{~d}, \mathrm{C}^{\mathrm{A} 6}\right), 155.06\left(\mathrm{~s}, \mathrm{C}^{\mathrm{B} 2}\right), 157.84\left(\mathrm{~s}, \mathrm{C}^{\mathrm{A} 2}\right)$.

[(4'-Chloro-2,2':6', 2"-terpyridine) (4'-(p-bromophenyl-)2,2':6', 2"-terpyridine)]ruthenium(II) hexafluorophosphate $15 \mathrm{c}$

4'-(p-Bromophenyl)-2,2':6',2"-terpyridineruthenium(III) chloride 14a (166.8 mg, 0.28 mmol) and $A \mathrm{mBF}_{4}(166.3 \mathrm{mg}, 0.854 \mathrm{mmol})$ were refluxed in acetone $(20 \mathrm{~mL})$ for $3 \mathrm{~h}$. The resulting $\mathrm{AgCl}$ was separated off, the solvent evaporated, and 4'-chloro-2,2': 6',2"-terpyridine $16(75.0 \mathrm{mg}, 0.28 \mathrm{mmol})$ and DMAc $(7.5 \mathrm{~mL})$ were added. The mixture was heated at $125^{\circ} \mathrm{C}$ for $36 \mathrm{~h}$. The resulting product was precipitated by adding $\mathrm{n}$-butanol $(40 \mathrm{~mL})$ and separated off by centrifuging. Anion exchange was carried out by dissolving the precipitate in DMAc $(5 \mathrm{~mL})$ and addition of a solution of $\mathrm{KPF}_{6}(0.4 \mathrm{~g})$ in water $(20 \mathrm{~mL})$. The precipitated product was centrifuged, washed with water $(20 \mathrm{~mL})$ and dried in vacuo $\left(\mathrm{P}_{4} \mathrm{O}_{10}\right)$. The yield was $239.0 \mathrm{mg}(81.5 \%)$. It could be purified by reprecipitation in DMAc / water and DMAc/n-butanol, or by refluxing in a mixture of $n$-butanol / water.

${ }^{1} \mathrm{H}$ NMR (DMSO- $\left.d_{6}\right): \delta=7.29\left(\mathrm{~m}, 4 \mathrm{H}, \mathrm{H}^{\mathrm{A} 5, \mathrm{~F} 5}\right), 7.57\left(\mathrm{~m}, 4 \mathrm{H}, \mathrm{H}^{\mathrm{A} 6, \mathrm{~F} 6}\right), 8.00\left(\mathrm{~d}, 2 \mathrm{H}, \mathrm{H}^{\mathrm{D} 3}\right)$, $8.06\left(\mathrm{~m}, 4 \mathrm{H}, \mathrm{H}^{\mathrm{A} 4, \mathrm{~F} 4}\right), 8.41\left(\mathrm{~d}, 2 \mathrm{H}, \mathrm{H}^{\mathrm{D} 2}\right), 8.92\left(\mathrm{~d}, 2 \mathrm{H}, \mathrm{H}^{\mathrm{F} 3}\right), 9.09\left(\mathrm{~d}, 2 \mathrm{H}, \mathrm{H}^{\mathrm{A} 3}\right), 9.36(\mathrm{~s}, 2 \mathrm{H}$, $\left.\mathrm{H}^{\mathrm{G} 3}\right), 9.48\left(\mathrm{~s}, 2 \mathrm{H}, \mathrm{H}^{\mathrm{B} 3}\right)$.

${ }^{13}$ C NMR (DMSO- $\left.d_{6}\right): \delta=120.92\left(\mathrm{~d}, \mathrm{C}^{\mathrm{B} 3}\right), 124.05\left(\mathrm{~s}, \mathrm{C}^{\mathrm{D} 4}\right), 124.16\left(\mathrm{~d}, \mathrm{C}^{\mathrm{G} 3}\right), 124.74(\mathrm{~d}$, $\left.\mathrm{C}^{\mathrm{A} 3}\right), 124.95\left(\mathrm{~d}, \mathrm{C}^{\mathrm{F} 3}\right), 127.59\left(\mathrm{~d}, \mathrm{C}^{\mathrm{A} 5}\right), 128.02\left(\mathrm{~d}, \mathrm{C}^{\mathrm{F5}}\right), 129.60\left(\mathrm{~d}, \mathrm{C}^{\mathrm{D} 2}\right), 132.25(\mathrm{~d}$, $\left.C^{D 3}\right), 135.18\left(s, C^{D 1}\right), 138.04\left(d, C^{A 4}\right.$ or $\left.{ }^{24}\right), 138.09\left(d, C^{A 4}\right.$ or $\left.F 4\right), 141.99\left(s, C^{G 4}\right)$, $145.76\left(\mathrm{~s}, \mathrm{C}^{\mathrm{B} 4}\right), 152.23\left(\mathrm{~d}, \mathrm{C}^{\mathrm{F} 6}\right), 152.37\left(\mathrm{~d}, \mathrm{C}^{\mathrm{A} 6}\right), 155.07\left(\mathrm{~s}, \mathrm{C}^{\mathrm{B} 2}\right), 155.72\left(\mathrm{~s}, \mathrm{C}^{\mathrm{G} 2}\right)$, $156.91\left(\mathrm{~s}, \mathrm{C}^{\mathrm{F} 2}\right), 157.75\left(\mathrm{~s}, \mathrm{C}^{\mathrm{A} 2}\right)$.

MS (ESI) $\mathrm{C}_{62} \mathrm{H}_{58} \mathrm{~N}_{4}: \mathrm{m} / \mathrm{z}=379.0\left(\mathrm{M}^{2+}\right)$.

4,4"-Bis[4'-(2,2':6':2"-terpyridine)]-2',5'-dihexyl-p-terphenyl-bis[4-chloro-2, 2':6',2"'terpyridinediruthenium(II)] hexafluorophosphate 17a

4,4"-Bis(2,2':6',2"-terpyridine)-2',5'-di-n-hexyl-p-terphenyl-bis-ruthenium(III) chloride 8 (37.9 mg, $0.0297 \mathrm{mmol}$ ) was activated by adding $\mathrm{AgBF}_{4}(0.120 \mathrm{~g}, 0.0594 \mathrm{mmol}$ ) and acetone $(20.0 \mathrm{~mL})$ and refluxing for $3 \mathrm{~h}$. At room temperature, the resulting $\mathrm{AgCl}$ was filtered off and the obtained solution was concentrated down to dryness. 4'-Chloro2,2':6',2"-terpyridine 16 (25.1 mg, $0.0938 \mathrm{mmol})$ and DMAc (30 mL) were added, and the mixture was heated for a further $30 \mathrm{~h}$ under reflux. After cooling down to room temperature, water $(20 \mathrm{~mL})$ was added, and the orange-red solution was separated from the organic precipitate by centrifuging. A solution of $\mathrm{KPF}_{6}(1.0 \mathrm{~g}, 5.4329 \mathrm{mmol})$ in water $(100 \mathrm{~mL})$ was added. The resulting orange-red precipitate was collected by centrifuging, washed with water $(20 \mathrm{~mL})$ and dried in vacuo $\left(\mathrm{P}_{4} \mathrm{O}_{10}\right)$. The yield was $41.7 \mathrm{mg}(64.4 \%)$. 
${ }^{1} \mathrm{H}$ NMR $\left(\mathrm{CD}_{3} \mathrm{CN}\right): \delta=0.90\left(\mathrm{t}, 6 \mathrm{H}, \mathrm{CH}_{3}\right), 1.28\left(\mathrm{~m}, 12 \mathrm{H}, \mathrm{CH}_{2}\right) 1.62\left(\mathrm{~m}, 4 \mathrm{H}, \beta-\mathrm{CH}_{2}\right) 2.81$ $\left(\mathrm{t}, 4 \mathrm{H}, \alpha-\mathrm{CH}_{2}\right), 722\left(\mathrm{~m}, 8 \mathrm{H}, \mathrm{H}^{\mathrm{A5}, \mathrm{F5}}\right), 7.39\left(\mathrm{~s}, 2 \mathrm{H}, \mathrm{H}^{\mathrm{E} 2}\right), 7.41\left(\mathrm{~d}, 4 \mathrm{H}, \mathrm{H}^{\mathrm{F} 6}\right.$ or $\left.\mathrm{H}^{\mathrm{A6}}\right), 7.49(\mathrm{~d}$, $4 \mathrm{H}, \mathrm{H}^{\mathrm{A6}}$ or $\left.\mathrm{H}^{\mathrm{F}}\right), 7.81\left(\mathrm{~d}, 4 \mathrm{H}, \mathrm{H}^{\mathrm{D} 3}\right), 7.97\left(\mathrm{~m}, 8 \mathrm{H}, \mathrm{H}^{\mathrm{A4}, \mathrm{F} 4}\right), 8.34\left(\mathrm{~d}, 4 \mathrm{H}, \mathrm{H}^{\mathrm{D} 2}\right), 8.53(\mathrm{~d}, 4 \mathrm{H}$, $\left.\mathrm{H}^{\mathrm{F} 3}\right), 8.69\left(\mathrm{~d}, 4 \mathrm{H}, \mathrm{H}^{\mathrm{A} 3}\right), 8.87\left(\mathrm{~s}, 4 \mathrm{H}, \mathrm{H}^{\mathrm{G} 3}\right), 9.09\left(\mathrm{~s}, 4 \mathrm{H}, \mathrm{H}^{\mathrm{B} 3}\right)$.

${ }^{1} \mathrm{H}$ NMR (DMSO- $\left.d_{6}\right): \delta=0.86\left(\mathrm{t}, 3 \mathrm{H}, \mathrm{CH}_{3}\right), 1.26\left(\mathrm{~m}, 12 \mathrm{H}, \mathrm{CH}_{2}\right), 1.59\left(\mathrm{~m}, 4 \mathrm{H}, \beta-\mathrm{CH}_{2}\right)$ $2.79\left(\mathrm{t}, 4 \mathrm{H}, \alpha-\mathrm{CH}_{2}\right), 7.31\left(\mathrm{t}, 4 \mathrm{H}, \mathrm{H}^{\mathrm{A} 5}\right), 7.34\left(\mathrm{t}, 4 \mathrm{H}, \mathrm{H}^{\mathrm{F}}\right), 7.38\left(\mathrm{~s}, 2 \mathrm{H}, \mathrm{H}^{\mathrm{E} 2}\right), 7.62(\mathrm{t}, 8 \mathrm{H}$, $\left.\mathrm{H}^{\mathrm{A} G, \mathrm{~F} 6}\right), 7.81\left(\mathrm{~d}, 4 \mathrm{H}, \mathrm{H}^{\mathrm{D} 3}\right), 8.09\left(\mathrm{~m}, 8 \mathrm{H}, \mathrm{H}^{\mathrm{A4}, \mathrm{F} 4}\right), 8.60\left(\mathrm{~d}, 4 \mathrm{H}, \mathrm{H}^{\mathrm{D} 2}\right), 8.94\left(\mathrm{~d}, 4 \mathrm{H}, \mathrm{H}^{\mathrm{F} 3}\right)$, $9.15\left(\mathrm{~d}, 4 \mathrm{H}, \mathrm{H}^{\mathrm{A} 3}\right), 9.38\left(\mathrm{~s}, 4 \mathrm{H}, \mathrm{H}^{\mathrm{G} 3}\right), 9.58\left(\mathrm{~s}, 4 \mathrm{H}, \mathrm{H}^{\mathrm{B} 3}\right)$.

${ }^{13} \mathrm{C} \mathrm{NMR}$ (DMSO- $\left.d_{6}\right): \delta=13.82\left(\mathrm{q}, \mathrm{CH}_{3}\right), 21.92,28.54,30.68,30.88,32.16\left(5 \mathrm{t}, \mathrm{CH}_{2}\right)$, $121.03\left(\mathrm{~d}, \mathrm{C}^{\mathrm{B} 3}\right), 124.20\left(\mathrm{~d}, \mathrm{C}^{\mathrm{G3}}\right), 124.78\left(\mathrm{~d}, \mathrm{C}^{\mathrm{A} 3}\right), 125.01\left(\mathrm{~d}, \mathrm{C}^{\mathrm{F3}}\right), 127.59\left(\mathrm{~d}, \mathrm{C}^{\mathrm{D} 2, A 5}\right)$, $128.07\left(\mathrm{~d}, \mathrm{C}^{\mathrm{F5}}\right), 129.90\left(\mathrm{~d}, \mathrm{C}^{\mathrm{D} 3}\right), 130.84\left(\mathrm{~d}, \mathrm{C}^{\mathrm{E} 2}\right), 134.62\left(\mathrm{~s}, \mathrm{C}^{\mathrm{b} 1}\right), 137.29\left(\mathrm{~s}, \mathrm{C}^{\mathrm{E3}}\right)$, $138.08\left(\mathrm{~d}, \mathrm{C}^{\mathrm{A} 4, \mathrm{~F} 4}\right), 139.91\left(\mathrm{~s}, \mathrm{C}^{\mathrm{E}}\right), 141.97\left(\mathrm{~s}, \mathrm{C}^{\mathrm{G} 4}\right), 143.25\left(\mathrm{~s}, \mathrm{C}^{\mathrm{D} 4}\right), 146.80\left(\mathrm{~s}, \mathrm{C}^{\mathrm{B} 4}\right)$, $152.21\left(\mathrm{~d}, \mathrm{C}^{\mathrm{F} 6}\right), 152.44\left(\mathrm{~d}, \mathrm{C}^{\mathrm{A} 6}\right), 155.04\left(\mathrm{~s}, \mathrm{C}^{\mathrm{B} 2}\right), 155.80\left(\mathrm{~s}, \mathrm{C}^{\mathrm{G} 2}\right), 157.00\left(\mathrm{~s}, \mathrm{C}^{\mathrm{F} 2}\right)$, $157.90\left(\mathrm{~s}, \mathrm{C}^{\mathrm{A2}}\right)$.

MS (ESI) $\mathrm{C}_{60} \mathrm{H}_{74} \mathrm{~N}_{12} \mathrm{Ru}_{2} \mathrm{Cl}_{2}: \mathrm{m} / \mathrm{z}=399.8\left(\mathrm{M}^{4+}\right)$.

[4'-(p-Bromophenyl)-2, 2':6',2"-terpyridine) (4-(p-bromophenyl)-6-phenyl-2,2'bipyridine)]ruthenium(II) hexafluorophosphate 15b

4'-(p-Bromophenyl)-2,2':6',2"-terpyridineruthenium(III) chloride 14a $(1027.0 \mathrm{mg}$, $1.7240 \mathrm{mmol}), \mathrm{AgBF}_{4}(1038.6 \mathrm{mg}, 5.3351 \mathrm{mmol})$ and acetone $(50 \mathrm{~mL})$ were refluxed for $3 \mathrm{~h}$. The precipitate was removed by filtration and the solution was concentrated down to dryness. DMAc $(40 \mathrm{~mL})$ and 4-p-bromophenyl-6-phenyl-2,2'-pyridine 13b $(666.7 \mathrm{mg}, 1.7215 \mathrm{mmol})$ were added, and the mixture was refluxed for $24 \mathrm{~h}$. After cooling down to room temperature, the resulting precipitate was collected by centrifuging and washed with DMAc $(10 \mathrm{~mL})$. Water $(50 \mathrm{~mL})$ was added to the combined solutions. The resulting solid was separated by centrifuging, washed with a mixture of water $(15 \mathrm{~mL})$ and DMAc $(10 \mathrm{~mL})$. The combined solid materials were redissolved in DMAc $(35 \mathrm{~mL})$, and a solution of water $(100 \mathrm{~mL})$, DMAc $(100 \mathrm{~mL})$ and $\mathrm{NH}_{4} \mathrm{PF}_{6}(5.0 \mathrm{~g})$ was added. The product precipitated nearly quantitatively from this mixture as hexafluorophosphate. It was isolated by centrifuging, washed with water $(2 \times 50 \mathrm{~mL})$ and dried in vacuo $\left(\mathrm{P}_{4} \mathrm{O}_{10}\right)$. The yield was $1411.7 \mathrm{mg}(80.2 \%)$. It may be recrystallized from acetonitrile : water $(=1: 1)$ or butanol.

${ }^{1} \mathrm{H}$ NMR (acetone- $\left.d_{6}\right): \delta=5.86\left(\mathrm{~d}, 1 \mathrm{H}, \mathrm{H}^{\mathrm{C} 6}\right), 6.54\left(\mathrm{t}, 1 \mathrm{H}, \mathrm{H}^{\mathrm{C5}}\right), 6.76\left(\mathrm{t}, 1 \mathrm{H}, \mathrm{H}^{\mathrm{C4}}\right), 7.22$ $\left(\mathrm{m}, 3 \mathrm{H}, \mathrm{H}^{\mathrm{A} 5, \mathrm{~A}^{\prime} 5, \mathrm{C}^{\prime} 5}\right), 7.69\left(\mathrm{~d}, 2 \mathrm{H}, \mathrm{H}^{\mathrm{A}^{\prime} 6, \mathrm{C}^{\prime} 6}\right), 7.78\left(\mathrm{~d}, 1 \mathrm{H}, \mathrm{H}^{\mathrm{A} 6}\right), 7.89\left(\mathrm{~m}, 6 \mathrm{H}, \mathrm{H}^{\mathrm{A}^{4} 4, \mathrm{C}^{\prime} 4, \mathrm{D}^{3}, \mathrm{D}^{\prime} 3}\right)$, $8.03\left(\mathrm{t}, 1 \mathrm{H}, \mathrm{H}^{\mathrm{A} 4}\right), 8.11\left(\mathrm{~d}, 1 \mathrm{H}, \mathrm{H}^{\mathrm{C} 3}\right), 8.26\left(\mathrm{~d}, 2 \mathrm{H}, \mathrm{H}^{\mathrm{D} 2}\right), 8.30\left(\mathrm{~d}, 2 \mathrm{H}, \mathrm{H}^{\mathrm{D}} 2\right), 8.76(\mathrm{~s}, 1 \mathrm{H}$, $\left.\mathrm{H}^{\mathrm{B} 5}\right), 8.90\left(\mathrm{~d}, 2 \mathrm{H}, \mathrm{H}^{\mathrm{A}^{\prime} 3, \mathrm{C}^{\prime} 3}\right), 8.96\left(\mathrm{~d}, 1 \mathrm{H}, \mathrm{H}^{\mathrm{A} 3}\right), 9.04\left(\mathrm{~s}, 1 \mathrm{H}, \mathrm{H}^{\mathrm{B} 3}\right), 9.28\left(\mathrm{~s}, 2 \mathrm{H}, \mathrm{H}^{\mathrm{B}^{\prime} 3, \mathrm{~B}^{\prime} 5}\right)$.

${ }^{13} \mathrm{C}$ NMR (acetone- $\left.d_{6}\right): \delta=116.28\left(\mathrm{~d}, \mathrm{C}^{\mathrm{B} 5}\right), 117.44\left(\mathrm{~d}, \mathrm{C}^{\mathrm{B} 3}\right), 120.33\left(\mathrm{~d}, \mathrm{C}^{\mathrm{B}^{3} 3, \mathrm{~B}^{\prime} 5}\right)$, $122.17\left(\mathrm{~d}, \mathrm{C}^{\mathrm{C} 4}\right), 123.75\left(\mathrm{~s}, \mathrm{C}^{\mathrm{D} 4}\right), 124.10\left(\mathrm{~d}, \mathrm{C}^{\mathrm{A}^{\prime} 3, \mathrm{C}^{\prime} 3}\right), 124.35\left(\mathrm{~s}, \mathrm{C}^{\mathrm{D}^{\prime} 4}\right), 124.49\left(\mathrm{~d}, \mathrm{C}^{\mathrm{A} 3}\right)$, $125.78\left(d, C^{C 3}\right), 127.14\left(d, C^{A 5, A^{\prime} 5, C^{\prime} 5}\right), 129.59\left(d, C^{C 5}\right), 129,96\left(d, C^{D 2}\right), 130,29(d$, $\left.\mathrm{C}^{\mathrm{D}^{2}}\right), 133.25\left(\mathrm{~d}, \mathrm{C}^{\mathrm{D} 3}\right), 133.36\left(\mathrm{~d}, \mathrm{C}^{\mathrm{A}^{4}, \mathrm{C}^{4} 4}\right), 135.54\left(\mathrm{~d}, \mathrm{C}^{\mathrm{D} 3}\right), 135.68\left(\mathrm{~d}, \mathrm{C}^{\mathrm{C} 6}\right), 137.87(\mathrm{~s}$, $\left.\mathrm{C}^{\mathrm{D}^{\prime} 1}\right), 138.06\left(\mathrm{~s}, \mathrm{C}^{\mathrm{D} 1}\right), 138.34\left(\mathrm{~d}, \mathrm{C}^{\mathrm{A4}}\right), 139.88\left(\mathrm{~s}, \mathrm{C}^{\mathrm{B} 6}\right), 146.53\left(\mathrm{~s}, \mathrm{C}^{\mathrm{B}^{4} 4}\right), 147.50(\mathrm{~s}$, $\left.\mathrm{C}^{\mathrm{B} 4}\right), 151.63\left(\mathrm{~d}, \mathrm{C}^{\mathrm{A}^{\prime} 6, \mathrm{C}^{\prime} 6}\right), 151.93\left(\mathrm{~d}, \mathrm{C}^{\mathrm{A} 6}\right), 154.65\left(\mathrm{~s}, \mathrm{C}^{\mathrm{A}^{2} 2, \mathrm{C}^{\prime} 2}\right), 155.20\left(\mathrm{~s}, \mathrm{C}^{\mathrm{B} 2}\right), 157.53$ $\left(\mathrm{s}, \mathrm{C}^{\mathrm{A} 2}\right), 158.18\left(\mathrm{~s}, \mathrm{C}^{\mathrm{A}^{\prime} 2, \mathrm{C}^{\prime} 6}\right), 165.10\left(\mathrm{~s}, \mathrm{C}^{\mathrm{B} 6}\right), 184.86\left(\mathrm{~s}, \mathrm{C}^{\mathrm{C} 1}\right)$.

${ }^{1} \mathrm{H}$ NMR (DMSO- $\left.d_{6}\right): \delta=5.70\left(\mathrm{~d}, 1 \mathrm{H}, \mathrm{H}^{\mathrm{C} 6}\right), 6.50\left(\mathrm{t}, 1 \mathrm{H}, \mathrm{H}^{\mathrm{C} 5}\right), 6.74\left(\mathrm{t}, 1 \mathrm{H}, \mathrm{H}^{\mathrm{C} 4}\right), 7.20$ $\left(\mathrm{m}, 3 \mathrm{H}, \mathrm{H}^{\mathrm{A}, \mathrm{A}^{\prime} 5, \mathrm{C}^{\prime} 5}\right), 7.47\left(\mathrm{~d}, 2 \mathrm{H}, \mathrm{H}^{\mathrm{A}^{\prime} 6, \mathrm{C}^{\prime} 6}\right), 7.58\left(\mathrm{~d}, 1 \mathrm{H}, \mathrm{H}^{\mathrm{A} 6}\right), 7.91\left(\mathrm{~m}, 6 \mathrm{H}, \mathrm{H}^{\mathrm{A}^{\prime} 4, \mathrm{C}^{\prime} 4, \mathrm{D}^{3}, \mathrm{D}^{\prime} 3}\right)$, 
$8.01\left(\mathrm{t}, 1 \mathrm{H}, \mathrm{H}^{\mathrm{A} 4}\right), 8.15\left(\mathrm{~d}, 1 \mathrm{H}, \mathrm{H}^{\mathrm{C} 3}\right), 8.35\left(\mathrm{~d}, 2 \mathrm{H}, \mathrm{H}^{\mathrm{D} 2}\right), 8.39\left(\mathrm{~d}, 2 \mathrm{H}, \mathrm{H}^{\mathrm{D}^{\prime} 2}\right), 8.79(\mathrm{~s}, 1 \mathrm{H}$, $\left.\mathrm{H}^{\mathrm{B} 5}\right), 8.97\left(\mathrm{~d}, 2 \mathrm{H}, \mathrm{H}^{\mathrm{A}^{\prime} 3, \mathrm{C}^{\prime} 3}\right), 9.03\left(\mathrm{~d}, 1 \mathrm{H}, \mathrm{H}^{\mathrm{A}^{3}}\right), 9.09\left(\mathrm{~s}, 1 \mathrm{H}, \mathrm{H}^{\mathrm{B} 3}\right), 9.33\left(\mathrm{~s}, 2 \mathrm{H}, \mathrm{H}^{\mathrm{B}^{\prime} 3, \mathrm{~B}^{\prime} 5}\right)$.

${ }^{13}$ C NMR (DMSO- $\left.d_{6}\right): \delta=115.01\left(\mathrm{~d}, \mathrm{C}^{\mathrm{B} 5}\right), 116.45\left(\mathrm{~d}, \mathrm{C}^{\mathrm{B} 3}\right), 119.11\left(\mathrm{~d}, \mathrm{C}^{\mathrm{B}^{\prime} 3, \mathrm{~B}^{\prime} 5}\right), 120.78$ $\left(\mathrm{d}, \mathrm{C}^{\mathrm{C} 4}\right), 122.49\left(\mathrm{~s}, \mathrm{C}^{\mathrm{D} 4}\right), 123.13\left(\mathrm{~s}, \mathrm{C}^{\mathrm{D}^{\prime} 4}\right), 123.37\left(\mathrm{~d}, \mathrm{C}^{\mathrm{A}^{\prime} 3, \mathrm{C}^{\prime} 3}\right), 123.75\left(\mathrm{~d}, \mathrm{C}^{\mathrm{A} 3}\right), 124.92$ $\left(\mathrm{d}, \mathrm{C}^{\mathrm{C} 3}\right), 126.27\left(\mathrm{~d}, \mathrm{C}^{\mathrm{A} 5, \mathrm{~A}^{\prime} 5, \mathrm{C}^{\prime} 5}\right), 128.36\left(\mathrm{~d}, \mathrm{C}^{\mathrm{C} 5}\right), 129.04\left(\mathrm{~d}, \mathrm{C}^{\mathrm{D} 2}\right), 129.43\left(\mathrm{~d}, \mathrm{C}^{\mathrm{D}^{\prime} 2}\right)$, $132.01\left(\mathrm{~d}, \mathrm{C}^{\mathrm{D} 3}\right), 132.18\left(\mathrm{~d}, \mathrm{C}^{\mathrm{A}^{\prime} 4, \mathrm{C}^{\prime} 4}\right), 134.22\left(\mathrm{~d}, \mathrm{C}^{\mathrm{C} 6}\right), 134.51\left(\mathrm{~d}, \mathrm{C}^{\mathrm{D} 3}\right), 136.13\left(\mathrm{~s}, \mathrm{C}^{\mathrm{D} 1}\right)$, $136.33\left(\mathrm{~s}, \mathrm{C}^{\mathrm{D} 1}\right), 137.31\left(\mathrm{~d}, \mathrm{C}^{\mathrm{A4}}\right), 137.93\left(\mathrm{~s}, \mathrm{C}^{\mathrm{B}^{\prime} 4}\right), 144.47\left(\mathrm{~s}, \mathrm{C}^{\mathrm{B} 4}\right), 146.39\left(\mathrm{~s}, \mathrm{C}^{\mathrm{C} 2}\right)$, $150.16\left(\mathrm{~d}, \mathrm{C}^{\mathrm{A}^{\prime} 6, \mathrm{C}^{\prime} 6}\right), 150.57\left(\mathrm{~d}, \mathrm{C}^{\mathrm{A} 6}\right), 153.01\left(\mathrm{~s}, \mathrm{C}^{\mathrm{B} 2}\right), 153.71\left(\mathrm{~s}, \mathrm{C}^{\mathrm{B} 2}\right), 155.96\left(\mathrm{~s}, \mathrm{C}^{\mathrm{A} 2}\right)$, $156.67\left(\mathrm{~s}, \mathrm{C}^{\mathrm{A}^{\prime} 2, \mathrm{C}^{\prime} 2}\right), 163.22\left(\mathrm{~s}, \mathrm{C}^{\mathrm{B}^{\prime} 6}\right), 184.04\left(\mathrm{~s}, \mathrm{C}^{\mathrm{C} 1}\right)$.

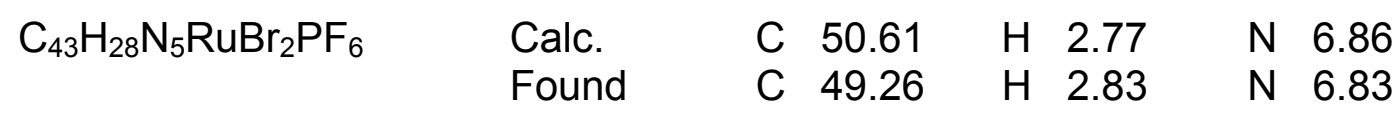

MS (ESI; $\left.\mathrm{CH}_{3} \mathrm{CN}\right): m / z=876.0\left(\mathrm{M}^{+}\right)$.

4,4"-Bis(6'-phenyl-2, 2'-bipyridine)-2', 5'-di-n-hexyl-p-terphenyl-bis(4'-chloro-2,2':6', 2"terpyridineruthenium(III) chloride) $\mathbf{1 7 b}$

4'-Chloro-2,2':6',2"-terpyridineruthenium(III) chloride 18 (95.5 mg, $0.2205 \mathrm{mmol}$ ), $\mathrm{AgBF}_{4}(139.3 \mathrm{mg}, 0.7157 \mathrm{mmol})$ and acetone $(25 \mathrm{~mL})$ were refluxed for $3 \mathrm{~h}$. The precipitate was removed by filtration, and the solution was concentrated down to dryness. DMAc (10 mL) and 4,4"-bis(6'-phenylbipyridine)-2',5'-di-n-hexyl-p-terphenyl (91.2 $\mathrm{mg}, 0.1062 \mathrm{mmol}$ ) were added, and the mixture was refluxed for $36 \mathrm{~h}$. After cooling down to room temperature, the solution was purified by centrifuging and water $(10 \mathrm{~mL})$ was added. The resulting solid was separated by centrifuging and washed with a mixture of water $(20 \mathrm{~mL})$ and DMAc $(20 \mathrm{~mL})$. The combined solid materials were redissolved in DMAc $(20 \mathrm{~mL})$, and a solution of $\mathrm{KPF}_{6}(3.23 \mathrm{~g}, 0.0176$ $\mathrm{mol})$ in water $(15 \mathrm{~mL})$ was added. The product precipitated nearly quantitatively from this mixture as hexafluorophosphate. It was isolated by centrifuging, washed with water $(2 \times 50 \mathrm{~mL})$ and dried in vacuo $\left(\mathrm{P}_{4} \mathrm{O}_{10}\right)$. The yield was $91.6 \mathrm{mg}(45.8 \%)$.

${ }^{1} \mathrm{H}$ NMR (acetone- $\left.d_{6}\right): \delta=0.88\left(\mathrm{t}, 6 \mathrm{H}, \mathrm{CH}_{3}\right), 1.29\left(\mathrm{~m}, 12 \mathrm{H}, \mathrm{CH}_{2}\right), 1.65\left(\mathrm{~m}, 4 \mathrm{H}, \beta-\mathrm{CH}_{2}\right)$, $2.84\left(\mathrm{t} ; 4 \mathrm{H}, \alpha-\mathrm{CH}_{2}\right), 5.81\left(\mathrm{~d}, 2 \mathrm{H}, \mathrm{H}^{\mathrm{C} 6}\right), 6.56\left(\mathrm{t}, 2 \mathrm{H}, \mathrm{H}^{\mathrm{C} 5}\right), 6.79\left(\mathrm{t}, 2 \mathrm{H}, \mathrm{H}^{\mathrm{C} 4}\right), 7.24(\mathrm{~m}, 6 \mathrm{H}$, $\left.\mathrm{H}^{\mathrm{A} 5, \mathrm{~F} 5}\right), 7.39\left(\mathrm{~s}, 2 \mathrm{H}, \mathrm{H}^{\mathrm{E} 2}\right), 7.77\left(\mathrm{~m}, 10 \mathrm{H}, \mathrm{H}^{\mathrm{A} 6, \mathrm{D} 3, \mathrm{~F} 6}\right), 7.91\left(\mathrm{t}, 4 \mathrm{H}, \mathrm{H}^{\mathrm{F} 4}\right), 8.03\left(\mathrm{t}, 2 \mathrm{H}, \mathrm{H}^{\mathrm{A} 4}\right)$, $8.14\left(\mathrm{~d}, 2 \mathrm{H}, \mathrm{H}^{\mathrm{C} 3}\right), 8.44\left(\mathrm{~d}, 4 \mathrm{H}, \mathrm{H}^{\mathrm{D} 2}\right), 8.77\left(\mathrm{~d}, 4 \mathrm{H}, \mathrm{H}^{\mathrm{F} 3}\right), 8.83\left(\mathrm{~s}, 2 \mathrm{H}, \mathrm{H}^{\mathrm{B} 5}\right), 8.97(\mathrm{~s}, 4 \mathrm{H}$, $\left.\mathrm{H}^{\mathrm{G} 3}\right), 8.98\left(\mathrm{~d}, 2 \mathrm{H}, \mathrm{H}^{\mathrm{A} 3}\right), 9.10\left(\mathrm{~s}, 2 \mathrm{H}, \mathrm{H}^{\mathrm{B} 3}\right)$. 13

C NMR (acetone- $\left.d_{6}\right): \delta=14.36\left(\mathrm{q}, \mathrm{CH}_{3}\right), 23.24,32.21,32.32,33.51\left(4 \mathrm{t}, \mathrm{CH}_{2}\right)$, $116.43\left(\mathrm{~d}, \mathrm{C}^{\mathrm{B} 5}\right), 117.62\left(\mathrm{~d}, \mathrm{C}^{\mathrm{B} 3}\right), 122.28\left(\mathrm{~d}, \mathrm{C}^{\mathrm{C} 4}\right), 122.90\left(\mathrm{~d}, \mathrm{C}^{\mathrm{G} 3}\right), 124.39\left(\mathrm{~d}, \mathrm{C}^{\mathrm{A} 3}\right)$, $124.50\left(\mathrm{~d}, \mathrm{C}^{\mathrm{F} 3}\right), 125.76\left(\mathrm{~d}, \mathrm{C}^{\mathrm{C} 3}\right), 127.09\left(\mathrm{~d}, \mathrm{C}^{\mathrm{A} 5}\right), 127.52\left(\mathrm{~d}, \mathrm{C}^{\mathrm{F5}}\right), 128.21\left(\mathrm{~d}, \mathrm{C}^{\mathrm{D} 2}\right)$, $129.62\left(d, C^{C 5}\right), 131.12\left(d, C^{D 3}\right), 132.02\left(d, C^{E 2}\right), 134.87\left(s, C^{C 4}\right), 135.58\left(d, C^{C 6}\right)$, $137.14\left(\mathrm{~s}, \mathrm{C}^{\mathrm{F} 4}\right), 138.46\left(\mathrm{~d}, \mathrm{C}^{\mathrm{A} 4}\right), 138.60\left(\mathrm{~s}, \mathrm{C}^{\mathrm{E} 3}\right), 141.41\left(\mathrm{~s}, \mathrm{C}^{\mathrm{G} 4}\right), 144.32\left(\mathrm{~s}, \mathrm{C}^{\mathrm{D} 4}\right)$, $147.61\left(\mathrm{~s}, \mathrm{C}^{\mathrm{B} 4}\right), 147.81\left(\mathrm{~s}, \mathrm{C}^{\mathrm{C} 2}\right), 151.62\left(\mathrm{~d}, \mathrm{C}^{\mathrm{F} 6}\right), 152.06\left(\mathrm{~d}, \mathrm{C}^{\mathrm{A} 6}\right), 155.17\left(\mathrm{~s}, \mathrm{C}^{\mathrm{B} 2}\right)$, $155.39\left(\mathrm{~s}, \mathrm{C}^{\mathrm{G} 2}\right), 157.20\left(\mathrm{~s}, \mathrm{C}^{\mathrm{F} 2}\right), 157.60\left(\mathrm{~s}, \mathrm{C}^{\mathrm{A} 2}\right), 165.04\left(\mathrm{~s}, \mathrm{C}^{\mathrm{B} 6}\right), 184.34\left(\mathrm{~s}, \mathrm{C}^{\mathrm{C} 1}\right)$.

${ }^{1} \mathrm{H}$ NMR (DMSO- $\left.d_{6}\right): \delta=0.85\left(\mathrm{t}, 6 \mathrm{H}, \mathrm{CH}_{3}\right), 1.26\left(\mathrm{~m}, 12 \mathrm{H}, \mathrm{CH}_{2}\right), 1.62\left(\mathrm{~m}, 4 \mathrm{H}, \beta-\mathrm{CH}_{2}\right)$, $2.84\left(\mathrm{t}, 4 \mathrm{H}, \alpha-\mathrm{CH}_{2}\right), 5.64\left(\mathrm{~d}, 2 \mathrm{H}, \mathrm{H}^{\mathrm{C} 6}\right), 6.53\left(\mathrm{t}, 2 \mathrm{H}, \mathrm{H}^{\mathrm{C} 5}\right), 6.77\left(\mathrm{t}, 2 \mathrm{H}, \mathrm{H}^{\mathrm{C} 4}\right), 7.20(\mathrm{t}, 2 \mathrm{H}$, $\left.\mathrm{H}^{\mathrm{A} 5}\right), 7.24\left(\mathrm{t}, 4 \mathrm{H}, \mathrm{H}^{\mathrm{F} 5}\right), 7.35\left(\mathrm{~s}, 2 \mathrm{H}, \mathrm{H}^{\mathrm{E} 2}\right), 7.53\left(\mathrm{~d}, 4 \mathrm{H}, \mathrm{H}^{\mathrm{F} 6}\right), 7.60\left(\mathrm{~d}, 2 \mathrm{H}, \mathrm{H}^{\mathrm{A} 6}\right), 7.74(\mathrm{~d}$, $\left.4 \mathrm{H}, \mathrm{H}^{\mathrm{D} 3}\right), 7.90\left(\mathrm{t}, 4 \mathrm{H}, \mathrm{H}^{\mathrm{F} 4}\right), 8.03\left(\mathrm{t}, 2 \mathrm{H}, \mathrm{H}^{\mathrm{A} 4}\right), 8.17\left(\mathrm{~d}, 2 \mathrm{H}, \mathrm{H}^{\mathrm{C} 3}\right), 8.51\left(\mathrm{~d}, 4 \mathrm{H}, \mathrm{H}^{\mathrm{D} 2}\right), 8.82$ $\left(\mathrm{d}, 4 \mathrm{H}, \mathrm{H}^{\mathrm{F} 3}\right), 8.86\left(\mathrm{~s}, 2 \mathrm{H}, \mathrm{H}^{\mathrm{B} 5}\right), 9.07\left(\mathrm{~d}, 2 \mathrm{H}, \mathrm{H}^{\mathrm{A} 3}\right), 9.15\left(\mathrm{~s}, 4 \mathrm{H}, \mathrm{H}^{\mathrm{G} 3}\right), 9.17\left(\mathrm{~s}, 2 \mathrm{H}, \mathrm{H}^{\mathrm{B} 3}\right)$.

${ }^{\mathrm{C}} \mathrm{NMR}\left(\mathrm{DMSO}-\mathrm{d}_{6}\right): \delta=13.82\left(\mathrm{q}, \mathrm{CH}_{3}\right), 21.90,28.52,30.70,30.85,32.10\left(5 \mathrm{t}, \mathrm{CH}_{2}\right)$, $115.19\left(\mathrm{~d}, \mathrm{C}^{\mathrm{B} 5}\right), 116.64\left(\mathrm{~d}, \mathrm{C}^{\mathrm{B} 3}\right), 120.92\left(\mathrm{~d}, \mathrm{C}^{\mathrm{C} 4}\right), 122.08\left(\mathrm{~d}, \mathrm{C}^{\mathrm{G} 3}\right), 123.63\left(\mathrm{~d}, \mathrm{C}^{\mathrm{F} 3}\right)$, 
$123.74\left(d, C^{A 3}\right), 124.92\left(d, C^{C 3}\right), 126.19\left(d, C^{A 5}\right), 126.67\left(d, C^{F 5}\right), 127.28\left(d, C^{D 2}\right)$, $128.44\left(\mathrm{~d}, \mathrm{C}^{\mathrm{C5}}\right), 129.73\left(\mathrm{~d}, \mathrm{C}^{\mathrm{D} 3}\right), 130.80\left(\mathrm{~d}, \mathrm{C}^{\mathrm{E2}}\right), 133.44\left(\mathrm{~s}, \mathrm{C}^{\mathrm{G} 4,7}\right), 134.13\left(\mathrm{~d}, \mathrm{C}^{\mathrm{C} 6}\right)$, $134.59\left(\mathrm{~d}, \mathrm{C}^{\mathrm{F} 4}\right), 135.44\left(\mathrm{~s}, \mathrm{C}^{\mathrm{D} 1}\right), 137.24\left(\mathrm{~s}, \mathrm{C}^{\mathrm{E3}}\right), 137.46\left(\mathrm{~d}, \mathrm{C}^{\mathrm{A4}}\right), 139.95\left(\mathrm{~s}, \mathrm{C}^{\mathrm{E1}}\right)$, $142.47\left(\mathrm{~s}, \mathrm{C}^{\mathrm{D} 4}\right), 145.68\left(\mathrm{~s}, \mathrm{C}^{\mathrm{B} 4}\right), 146.49\left(\mathrm{~s}, \mathrm{C}^{\mathrm{C} 2}\right), 150.13\left(\mathrm{~d}, \mathrm{C}^{\mathrm{F} 6}\right), 150.82\left(\mathrm{~d}, \mathrm{C}^{\mathrm{A} 6}\right)$, $153.67\left(\mathrm{~s}, \mathrm{C}^{\mathrm{B} 2}\right), 153.75\left(\mathrm{~s}, \mathrm{C}^{\mathrm{G} 2}\right), 155.70\left(\mathrm{~s}, \mathrm{C}^{\mathrm{F} 2}\right), 156.02\left(\mathrm{~s}, \mathrm{C}^{\mathrm{A} 2}\right), 163.17\left(\mathrm{~s}, \mathrm{C}^{\mathrm{B} 6}\right)$, $183.53\left(\mathrm{~s}, \mathrm{C}^{\mathrm{C} 1}\right)$.

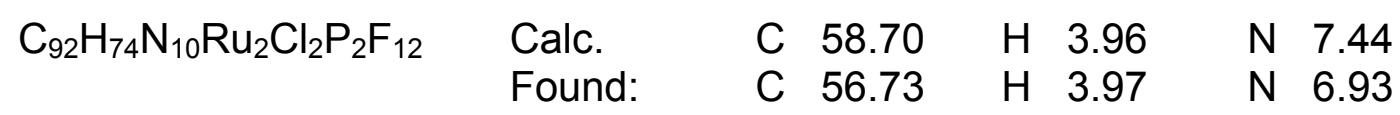

MS (ESI; $\left.\mathrm{CH}_{3} \mathrm{CN}\right): \mathrm{m} / \mathrm{z}=797.2\left(\mathrm{M}^{2+}\right)$.

\section{Synthesis of polymer 7}

4,4"-Bis(2,2':6',2"-terpyridine)-2',5'-di-n-hexyl-p-terphenyl-bis-ruthenium(III) chloride 8 (238.9 mg, $0.1872 \mathrm{mmol}$ ) was activated by adding $\mathrm{AgBF}_{4}(238.3 \mathrm{mg}, 1.21697 \mathrm{mmol})$ and acetone $(35 \mathrm{~mL})$ and refluxing for $3 \mathrm{~h}$. The resulting solid was separated off, and the obtained solution was concentrated down to dryness. The brownish-black solid was dissolved in DMAc $(25.2 \mathrm{~mL})$, resulting in a monomer concentration of 0.00743 $\mathrm{mol} / \mathrm{L}$. This solution was used for the subsequent polymerization.

To the above solution of activated $\mathbf{8}^{*}$ in DMAc $(5.0 \mathrm{~mL}), 4,4$ "-bis(6'-phenyl-2,2'bipyridine)-2',5'-di-n-hexyl-p-terphenyl 6 (66.9 mg, $0.07787 \mathrm{mmol})$, dissolved in DMA $(25 \mathrm{~mL})$, was added, heated and refluxed for $24 \mathrm{~h}$. Using a syringe pump, further metal monomer in DMAc (2.2 mL of the above solution) was added within $9 \mathrm{~h}$, and a further $3.5 \mathrm{~mL}$ were slowly added within $36 \mathrm{~h}$. After $36 \mathrm{~h}$ reaction time, a further 2.7 $\mathrm{mL}$ of the basic solution were added within $5 \mathrm{~h}$, and reaction was continued for a further $12 \mathrm{~h}$. The reaction mixture was allowed to cool down to room temperature and was slowly dropped into water $(1000 \mathrm{~mL})$. The solid was collected, washed with water and dried in vacuo $\left(\mathrm{P}_{4} \mathrm{O}_{10}\right)$. The yield was $103.3 \mathrm{mg}(62.9 \%)$.

${ }^{1} \mathrm{H}$ NMR (DMSO- $\left.d_{6}\right): \delta=0.85\left(\mathrm{t}, 6 \mathrm{H}, \mathrm{CH}_{3}\right), 1.26\left(\mathrm{~m}, 12 \mathrm{H}, \mathrm{CH}_{2}\right), 1.62\left(\mathrm{~m}, 4 \mathrm{H}, \beta-\mathrm{CH}_{2}\right)$, $2.84\left(\mathrm{t}, 4 \mathrm{H}, \alpha-\mathrm{CH}_{2}\right), 5.74\left(\mathrm{~m}, 1 \mathrm{H}, \mathrm{H}^{\mathrm{C} 6}\right), 6.53\left(\mathrm{~m}, 1 \mathrm{H}, \mathrm{H}^{\mathrm{C} 5}\right), 6.77\left(\mathrm{~m}, 1 \mathrm{H}, \mathrm{H}^{\mathrm{C} 4}\right), 7.23(\mathrm{~m}$, $\left.3 \mathrm{H}, \mathrm{H}^{\mathrm{A} 5, \mathrm{~A}^{\prime} 5}\right), 7.35\left(\mathrm{~m}, 4 \mathrm{H}, \mathrm{H}^{\mathrm{E} 2, \mathrm{E}^{\prime} 2}\right), 7.51\left(\mathrm{~m}, 2 \mathrm{H}, \mathrm{H}^{\mathrm{A}^{\prime} 6}\right), 7.62\left(\mathrm{~m}, 1 \mathrm{H}, \mathrm{H}^{\mathrm{A} 6}\right), 7.73(\mathrm{~m}, 4 \mathrm{H}$, $\left.\mathrm{H}^{\mathrm{D}^{\prime} 3, \mathrm{D} 3}\right), 7.92\left(\mathrm{~m}, 2 \mathrm{H}, \mathrm{H}^{\mathrm{A}^{\prime} 4}\right), 8.04\left(\mathrm{~m}, 1 \mathrm{H}, \mathrm{H}^{\mathrm{A} 4}\right), 8.19\left(\mathrm{~m}, 1 \mathrm{H}, \mathrm{H}^{\mathrm{C} 3}\right), 8.55(\mathrm{~m}, 4 \mathrm{H}$, $\left.\mathrm{H}^{\mathrm{D} 2, \mathrm{D}^{\prime} 2}\right), 8.86\left(\mathrm{~m}, 1 \mathrm{H}, \mathrm{H}^{\mathrm{B} 5}\right), 9.03\left(\mathrm{~m}, 2 \mathrm{H}, \mathrm{H}^{\mathrm{A}^{\prime} 3}\right), 9.08\left(\mathrm{~m}, 1 \mathrm{H}, \mathrm{H}^{\mathrm{A} 3}\right), 9.17\left(\mathrm{~m}, 1 \mathrm{H}, \mathrm{H}^{\mathrm{B} 3}\right)$, $9.41\left(\mathrm{~m}, 2 \mathrm{H}, \mathrm{H}^{\mathrm{B}^{\prime} 3}\right)$.

Acknowledgement: We would like to thank the Fonds der Chemischen Industrie e.V. $(\mathrm{FCl})$ and the Vereinigung der Freunde der TU Darmstadt e.V. for financial support of this work.

[1] Hearshaw, M. A.; Moss, J. R.; J. Chem. Soc., Chem. Commun. 1999, 1.

[2] Rehahn, M.; Acta Polym. 1998, 49, 201.

[3] Balzani, V.; Juris, A.; Venturi, M.; Campagna, S.; Serroni, S.; Chem. Rev. 1996, 96, 759.

[4] Manners, I.; Angew. Chem. 1996, 108, 1713.

[5] Harriman, A.; Ziessel, R.; J. Chem. Soc., Chem. Commun. 1996, 1707.

[6] Lehn, J.-M.; "Supramolecular Chemistry", VCH, Weinheim 1995. 
[7] Constable, E. C.; Chargill Thompson, A. M. W.; J. Chem. Soc., Dalton Trans. 1995, 1615.

[8] Constable, E. C.; Cargill Thompson, A. M. W.; Harveson, P.; Macko, L.; Zehnder, M.; Chem. Eur. J. 1995, 1, 360.

[9] Sauvage, J.-P.; Collin, J.-P.; Chambron, J.-C.; Guillerez, S.; Coudret, C.; Balzani, V.; Barigelletti, F.; DeCola, L.; Flamigni, L.; Chem. Rev. 1994, 94, 993.

[10] Balzani, V.; Credi, A.; Scandola, F.; in "Transition Metals in Supramolecular Chemistry”, Fabbrizzi, L.; Poggi, A.; Eds.; Kluwer, Dordrecht 1994.

[11] Constable, E. C.; in "Transition Metals in Supramolecular Chemistry", Fabbrizzi, L.; Poggi, A.; Eds.; Kluwer, Dordrecht 1994, p. 81.

[12] Schütte, M.; Kurth, D. G.; Linford, M. R.; Cölfen, H.; Möhwald, H.; Angew. Chem. 1998, 110, 3058.

[13] Salditt, T.; An, Q.; Plech, A.; Eschbaumer, C.; Schubert, U. S.; J. Chem. Soc., Chem. Commun. 1998, 2731.

[14] Knof, U.; Zelewski, A.; Angew. Chem. 1999, 111, 312.

[15] Velten, U.; Rehahn, M.; J. Chem. Soc., Chem. Commun. 1996, 2639.

[16] Velten, U.; Lahn, B.; Rehahn, M.; Macromol. Chem. Phys. 1997, 198, 2789.

[17] Knapp, R.; Schott, A.; Rehahn, M.; Macromolecules 1996, 29, 478.

[18] Kelch, S.; Rehahn, M.; Macromolecules 1997, 30, 6185.

[19] Kelch, S.; Rehahn, M.; Macromolecules 1999, 32, 5818.

[20] Schubert, U. S.; Heller, M.; Chem. Eur. J. 2001, 7, 5253.

[21] Heller, M.; Schubert, U. S.; e-Polymers 2002, no. 027.

[22] Gohy, J.-F.; Lohmeijer, B. G. G.; Schubert, U.S.; Macromolecules 2002, 35, 4560.

[23] Gohy, J.-F.; Lohmeijer, B. G. G.; Varshney, S. K.; Schubert, U. S.; Macromolecules 2002, 35, 7427.

[24] Encinas, S.; Flamigni, L.; Barigelletti F.; Constable E. C.; Housecroft, C. E.; Schofield, E. R.; Figgemeier E.; Fenske D.; Neuburger M.; Vos, J. G.; Zehnder, M.; Chem. Eur. J. 2002, 8, 137.

[25] Newkome, G. R.; Cho T.J.; Moorefield, C. N.; Cush, R.; Russo, P. S.; Godinez, L. A.; Saunders, M. J.; Mohapatra, P.; Chem. Eur. J. 2002, 8, 2946.

[26] Lainé, P.; Bedioui F.; Ochsenbein, P.; Marvaud, V.; Bonin, M.; Amouyal, E.; J. Am. Chem. Soc. 2002, 124, 1364.

[27] Constable, E. C.; Cargill Thompson, A. M. W.; New J. Chem. 1996, 20, 65.

[28] Constable, E. C.; Cargill Thompson, A. M. W.; Supramol. Chem. 1994, 4, 95.

[29] Constable, E. C.; Hannon, M. J.; Inorg. Chim. Acta 1993, 211, 101.

[30] Constable, E. C.; Dunne, S. J.; Rees, D. G. F.; Schmitt, C. X.; J. Chem. Soc., Chem. Commun. 1996, 1169.

[31] Constable, E. C.; Cargill Thompson, A. M. W.; Greulich, S.; J. Chem. Soc., Chem. Commun. 1993, 1444.

[32] Patoux, C.; Launay, J.-P.; Beley, M.; Chorodowski, S.; Collin, J.-P.; James, S.; Sauvage, J. P.; J. Am. Chem. Soc., 1998, 120, 3717. 
[33] Barigelleti, F.; Flamigni, L.; Guardigli, M.; Juris, A.; Beley, M.; Chorodowski, S.; Kimmes, A.; Collin, J.-P., Sauvage, J. P.; Inorg. Chem., 1996, 35, 136.

[34] Beley, M.; Chodorowski, S.; Collin, J.-P.; Sauvage, J.-P.; Flamigni, L.; Barigelletti, F.; Inorg. Chem. 1994, 33, 2543.

[35] Beley, M.; Collin, J.-P.; Sauvage, J.-P.; Inorg. Chem. 1993, 32, 4539.

[36] Collin, J.-P.; Beley, M.; Sauvage, J.-P.; Barigelletti, F.; Inorg. Chim. Acta 1991, 186, 91.

[37] Beley, M.; Collin, J.-P.; Louis, R.; Metz, B.; Sauvage, J.-P.; J. Am. Chem. Soc. 1991, 113, 8521.

[38] Mikel, C.; Potvin, P. G.; Inorg. Chim. Acta 2001, 325, 1.

[39] Bonnefous, C.; Abdellatif, C.; Thummel, R. P.; Inorg. Chem. 2001, 40, 5851.

[40] Barigelleti, F.; Ventura, B.; Collin, J.-P.; Kayhanian, R.; Gavina, P.; Sauvage, J.P.; Eur. J. Inorg. Chem. 2000, 1, 113.

[41] Jahng, Y.; Park, J. G.; Bull. Korean Chem. Soc. 1999, 20, 1200.

[42] Laemmel, A.-C.; Collin, J.-P.; Sauvage, J.-P.; Eur. J. Inorg. Chem. 1999, 3, 383.

[43] Dixon, I. M.; Collin, J.-P.; Journal of Porphyrins and Phthalocyanines 2001, 5, 600.

[44] Jahng, Y.; Park, J.; Bull. Korean Chem. Soc. 1999, 20, 1200.

[45] Mamo, A.; Stefio, I.; Poggi, A.; Tringali, C.; Di Pietro C.; Campagna, S.; New J. Chem. 1997, 21, 1173.

[46] Jonaiti, A.; Geoffroy, M.; Collin, J.-P.; Inorg. Chim. Acta 1996, 245, 69.

[47] Rehahn, M.; Schlüter, A.-D.; Wegner, G.; Makromol. Chem. 1990, 191, 1991.

[48] Schlüter, A.-D.; Wegner, G.; Acta Polym. 1993, 44, 59.

[49] Miyaura, N.; Suzuki, A.; Chem. Rev. 1995, 95, 2457.

[50] Beley, M.; Chodorowski, S.; Collin, J.-P.; Sauvage, J.-P.; Flamigni, L.; Barigelletti, F.; Inorg. Chem. 1994, 33, 2543.

[51] Juris, A.; Balzani, V.; Barigelletti, F.; Campagna, S.; Balser, P.; von Zelewsky, A.; Coord. Chem. Rev. 1988, 84, 85.

[52] Kröhnke, F.; Gross, F.; Chem. Ber. 1959, 92, 22.

[53] Korall, P.; Börje, A.; Akermark, B.; Acta Chem. Scand. 1997, 51, 76.

[54] (a) Kohler, E. P.; Chadwell, H. M.; "Organic Syntheses", Coll.Vol.I, Wiley, New York 1941, 78. (b) Silver, N. L.; Boykin jr., D. W.; J. Org. Chem. 1970, 35, 759.

[55] Sullivan, B. P.; Calvert, J. M.; Meyer, T. J.; Inorg. Chem. 1980, 19, 1404. 